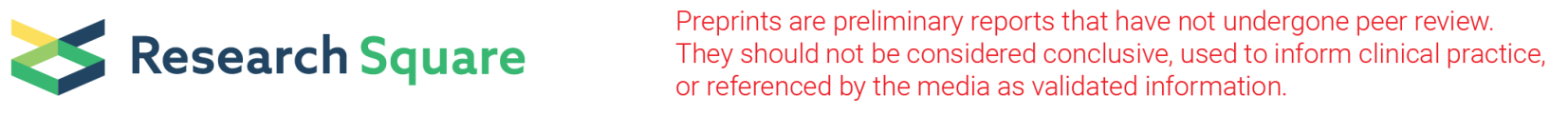

\title{
Clone And Function Verification of The OPR Gene Related to Linoleic Acid Synthesis
}

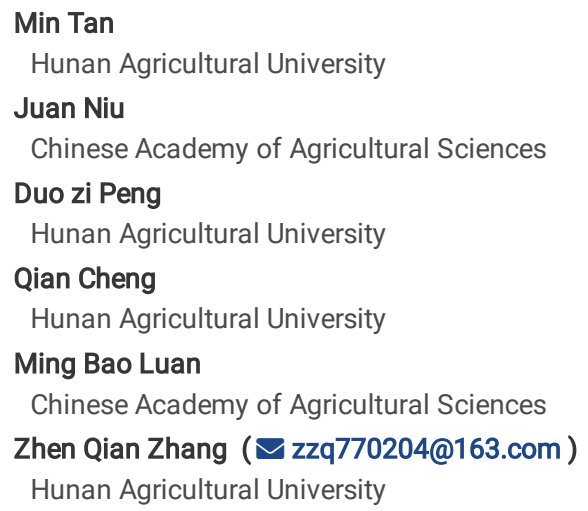

Research Article

Keywords: rapeseed, OPR gene, linoleic acid, RNAi, overexpression

Posted Date: November 17th, 2021

DOI: https://doi.org/10.21203/rs.3.rs-1058925/v1

License: (c) (1) This work is licensed under a Creative Commons Attribution 4.0 International License. Read Full License 


\section{Abstract}

Background: Fatty acid composition and content affect rapeseed oil quality. Fatty acid synthesis-related genes in rapeseed have been studied globally by researchers. Nevertheless, rapeseed oil is mainly composed of seven different fatty acids, and each fatty acid was regulated by different genes, furthermore different fatty acid contents affect each other, which needs continuous and in-depth research to obtain more clear results.

Results: In this paper, broad-scale miRNA expression profiles were constructed and 21 differentially expressed miRNAs were detected. GO enrichment analysis showed that most up-regulated proteins were involved in transcription factor activity and catalytic activity. KEGG pathway enrichment analysis indicated that 20 pathways involving 36 target genes were enriched, of which the bna00592 pathway may be involved in fatty acid metabolism. The results were verified using a Quantitative Real-time PCR (RT-PCR) analysis, and it was found that the target gene of bna-miR156b>c $>g$ was the $O P R$ (12-oxo-phytodienoic acid reductase). Four copies of $O P R$ gene were found, and the over-expression vectors (pCAMBIA1300-35s-OPR and pCAMBIA1300-RNAi-OPR) were constructed to verify their functions. In $\mathrm{T}_{1}$ and $\mathrm{T}_{2}$ plants, OPR-OE (OPR Over-Expression strain) significantly increased linoleic acid content ( $\left.\mathrm{T}_{1} 12.56 \%, \mathrm{~T}_{2} 7.185 \%\right)$ and $\mathrm{OPRi}$ (OPRi RNA-interference strain) decreased linoleic acid content $\left(\mathrm{T}_{1} 5.98 \%, \mathrm{~T}_{2} 0.86 \%\right)$.

Conclusions: This is the first study to provide four copies of the OPR gene that regulates LA metabolism, can be used for the molecular mechanism of LA and optimizing fatty acid profiles in oilseed for breeding programs.

\section{Background}

Brassica campestris $L$. (rapeseed) is one of the most important oil crops in the world $[1,2]$. The quality of rapeseed oil mainly depends on its fatty acid composition, especially the proportion of three main unsaturated fatty acids: oleic acid $\left(\mathrm{C}_{18: 1}\right)$, linoleic acid $\left(\mathrm{C}_{18: 2}\right)$, and linolenic acid $\left(\mathrm{C}_{18: 3}\right)$ [3]. Many studies have shown that rapeseed oil with a high unsaturated fatty acid content will have better health effects and can prevent the occurrence of cardiovascular diseases [4]. Linoleic acid (LA) can prevent or reduce the incidence of cardiovascular diseases and being used for the prevention and treatment of hypertension, hyperlipidemia, angina pectoris, coronary heart disease, atherosclerosis, and senile obesity $[5,6]$. LA can be used as a precursor of ultra-long chain polyunsaturated fatty acids. a-linolenic acid (ALA) and y-linolenic acid (GLA) have been hydrogenated from linoleic acid using desaturase [7].

miRNAs are short noncoding regulatory RNAs that regulate gene expression via post-transcriptional repression [8, 9]. In plants, miRNAs are involved in various biological processes, including the regulation of plant development [10], architecture formation [11], photosynthesis [9], tolerance to biotic and abiotic stresses $[12,13,14,15]$. In recent years, several new miRNAs have been found in oilseed rape $[16,17,18]$. The process of seed development is a period that starts at embryo development and ends when dry seeds are mature; it is a key stage that affects the seed size, oil production, protein content, and antinutritional accumulation of rapeseed. Furthermore, gene expression changes during seed development [19,20,21]. Recently, miRNAs and their target transcripts involved in fatty acid and lipid metabolism have been studied in different development of B.napus seed, which is considered the third largest oil crop worldwide [22, 23]. Some miRNAs involved in acetyl-CoA generate and carbon chain desaturase were also observed; nevertheless, the total number of known miRNAs and their functions in B. napus are still unknown [23].

The development of molecular biology technology has greatly promoted the research on LA breeding in rapeseed. ( $\nabla)$ In terms of mining the function of genes, a study showed significant correlation between FAD3 and LA content [24], while another study revealed that the overexpression of SsDGAT1 significantly affected LA content (about 16\%) [25]. McD6DES generates a double bond at the carboxyl end of LA, which reduces the LA content [26]; BJULFY increases LA content (approximately 5\%) [27]. The single nucleotide mutation of FAD3 exon from $\mathrm{G}$ to A was screened from the rapeseed "Alboglabra" treated with an Ethyl Methyl Sulfone (EMS) solution, and the mutant materials with high LA content and low alanine content (about 2.0\%) were obtained [28]. ( $\nabla$ ) In terms of screening the genes, a genome wide association study (GWAS) discovered 53 and 24 SNP related to LA in 2013Cq and 2014Cq rapeseed materials, respectively [29]; when combined with RT-PCR, 95 candidate genes were found to be highly related to LA and other fatty acid metabolism [30]. ( () In terms of locating the genes, FAD2 gene on chromosome A05 was found to be associated with LA content, and a minor gene regulating LA content was found on chromosome A09 [31]; twenty QTLs related to LA were detected using two spring rapeseed varieties, "Polo" and "Topas", and subsequently distributed in seven linkage groups: A01, A02, A03, A05, C01, C03, and C09 [32].

miRNA technology has been adopted to find several miRNAs in enzymes used for carbon chain desaturation, while being used in studies on fatty acid and lipid metabolism in rapeseed [22]. Employing this technology can be conducive to the breeding of rapeseed [23]. Therefore, we sequenced rapeseed material using miRNA technology. Then, we excavated four copies of $O P R$ genes. The four copies of gene overexpression and RNAi vectors were transferred into $A$. thaliana. This is the first study to report that all copies of $O P R$ gene could directly regulate the synthesis of linoleic acid. These findings will enhance the understanding of LA metabolism in rapeseed.

\section{Results}

\section{Overview of sRNA sequencing results}

We have already upload data and ensure the deposited data is made public (NCBI) : https://www.ncbi.nlm.nih.gov/sra/PRJNA760803, accession number】 PRJNA760803. A total of 22,744,964 (low oleic acid rapeseed materials, A) and 26,060,122 (HOAR materials, B) raw reads were generated from the sequencing machine. After removing the adaptor sequences, filtering out low quality tags, and cleaning up sequences derived from adaptor ligation, 20,912,776 (A) and 23,710,938 (B) clean reads were obtained. Consequently, the bioinformatic analysis of these clean reads were carried out (Table 1). The size distribution patterns of the original and unique reads were displayed in Figure 1A. Small RNAs (24 nt) were the most abundant in all the samples. In addition, the clean reads exhibited $87.45 \%$ (A) and $88.26 \%$ (B) homology with the reference genome sequences. The sRNA sequencing results were of high quality and reliable and can be used for further functional analysis. 


\section{Differentially expressed miRNAs identification and their function analysis}

The clustering analysis method was used to investigate the similarity between samples by calculating the differential miRNA distance between low oleic acid rapeseed (A) and HOAR (B) (Figure 1B). As shown, three samples of high or low oleic acid contents were found in a cluster, suggesting that these miRNAs might have similar biological functions.

After applying a P value $<0.05$ and an absolute value of log2 (treatment/control) greater than 1.5 to identify differentially expressed miRNAs, 21 differentially expressed miRNAs (8.39\% of the total) were detected (Table 2, Supplemental Table 2); their frequencies were calculated using TPM (Table 3). Among them, nine genes (42.86\%) were up-regulated and 12 (57.14\%) were down-regulated in HOAR materials (Figure 1C). Briefly, 17 miRNAs (including NC_027774.1_24533, NC_027757.1_266, bna-miR156b>bna-miR156c>bna-miR156g(bna-miR156b>c>g), NC_027774.1_24533*, NC_027769.1_17408*, bnamiR156a, bna-miR162a, NC_027769.1_17408, bna-miR172d, bna-miR824, bna-miR166f, bna-miR396a, bna-miR169m, bna-miR160a>bna-miR160b>bnamiR160c>bna-miR160d (bna-miR160a>b>c>d), NC_027760.1_5272, NC_027768.1_15573, and NW_013650328.1_26640*) and 358 target genes were obtained.

The target genes were then subjected to GO functional and KEGG Pathway analyses. In many cases, multiple terms were assigned to the same miRNA. Thus, 133 putative target genes were associated with 21 differentially expressed miRNAs and distributed into the following subcategories: 62 "Biological process", 32 "Cellular component", and 39 "Molecular function" (Figure 1D). Under "Biological process", most of the target genes were related to "transcription", and "regulation of transcription". Within the "Cellular component" category, "nucleus" and "cytosol" were observed as much as "cytoplasm". Among genes in the "Molecular function" category, most potential functions were related to "transcription factor activity", "DNA binding", and "Catalytic activity". The distribution of target genes indicated that rapeseed underwent active metabolization.

The KEGG pathway enrichment analysis indicated that 20 pathways involving 36 target genes were enriched, including "alpha-Linolenic acid metabolism" (7 target genes), "Phagosome" (3 target genes), "Oxidative phosphorylation" (3 target genes), "Oxidative phosphorylation" (3 target genes), and “Protein processing in endoplasmic reticulum" (3 target genes). The fifteen target genes may be related to fatty acid metabolism: "alpha-linolenic acid metabolism" (7 genes), “Oxidative phosphorylation” (3 genes), “Carbon metabolism” (2 genes), “Citrate cycle (TCA cycle)” (1 gene), "Glycerolipid metabolism” (1 gene), and "Glycolysis / Gluconeogenesis" (1 gene). The top 20 KEGG enrichments (Figure 2A) show that a-Linolenic acid metabolism is the most significant, suggesting that bna00592 KEGG pathway may be involved in fatty acid metabolism in rapeseed (Figure 2B).

\section{Expression pattern of bna-miR156b>c>g gene was detected by RT-PCR}

To confirm the results of the miRNA sequence analysis, 21 annotated differentially expressed miRNAs were compared to the $B$. napus genome using BLAST [33] (Figure 2B).

Most expression trends of the RT-PCR analysis results agreed with the miRNA sequencing data (NC_027757.1_266, NC_027760.1_5272, NC_027760.1_5272*, NC_027761.1_6665, NC_027768.1_15573, NC_027769.1_17408, NC_027769.1_17408*, NC_027774.1_24533, NC_027774.1_24533*,

NW_013650328.1_26640*, bna-miR162a, bna-miR167a>b, bna-miR169m, bna-miR172d, bna-miR396a, bna-miR824.), In addition, among the 13 miRNAs with significant difference, 9 had target genes (NC_027760.1_5272, NW_013650328.1_26640*, bna-miR156b>c>g, bna-miR166f, bna-miR169m, bna-miR396a, bnamiR824, bna-miR156a, and bna-miR160a>b>c>d), which may be the novel miRNAs related to fatty acids.

Moreover, the expressions of fatty acid metabolism related to differential miRNAs, such as bna- miR396a, bna-miR156b>c>g, and their target genes, were studied in different developmental stages (Figure 2C). The bna-miR396a has opposite expression pattern with its target gene, at first, the bna-miR396 had upregulated expression, until the bud stage reached the peak, and the expression decreased with the growth stage; $b n a-m i R 156 b>c>g$ had an opposite expression pattern with its target gene, it had down-regulated expression in the whole growth stages, and the expression decreased with the growth stages. Differentially expressed miRNAs and their target genes were related to fatty acid metabolism in bna-mi156b>c>g at different developmental stages (Figure 1C). In contrast

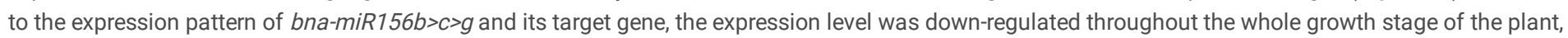
and the expression level gradually decreased with the growth process of rapeseed.

\section{Cloning of $O P R$ genes in rapeseed and bioinformatic analysis}

Target gene: bna-miR156b>c>g was cloned by miRNA sequencing, and four copies were detected: GSBRNA2T00012422001, GSBRNA2T00135385001, GSBRNA2T00082938001, and GSBRNA2T00094910001, which were named OPR1, OPR2, OPR3, and OPR4, respectively. Both OPR1 and OPR3 were 1119 bp, OPR2 and OPR4 were $1125 \mathrm{bp}$ and $1122 \mathrm{bp}$, respectively (Figure 3A).

DNAMAN 7.0 software was used to compare the cloned target sequence with the rapeseed sequence published on the Brassica napus Genome Browser website. Different base position (Figure 3B), homology were more than 99\% with the published sequences (Figure 3C). OPR1, OPR3, OPR4 had no base difference with the published sequence, there were 10 base differences between OPR2 and published sequence and the homology was $99.11 \%$. Preliminary identification of $O P R 2$ and $O P R 3$ were located in A genome and OPR4 and OPR1 in C genome was conducted.

The number of four copies of $O P R$ gene amino acids ranged from 372 bp to $374 \mathrm{bp}$, with a molecular weight of about 41 ku; The encoded amino acids were acidic $(<7)$, unstable $(<40)$, exhibited a fat coefficient of about 75 , and belonged to fat-soluble proteins. Predicted subcellular localization of proteins were encoded by different copies of $O P R$ genes and we found that these four proteins were located in the cytoplasm. We found that the four copies were all extracellular proteins without a transmembrane structure. Predicted protein secondary structures were summarized in Table 4. 
The predicted tertiary structure model of the protein shows that the tertiary structures of $O P R 1, O P R 2, O P R 3$, and $O P R 4$ were all adapted to the 12-0-plant dienoate reductase model (integrated with the crystal structure of At1g76680 protein in A. thaliana), but their conformations were slightly different (Figure 3D). It has been reported that the protein structure $A$. thaliana of $A t 1 g 76680$ is similar to that of yeast ScOYE1 [34].

\section{Vector construction and transformation of $A$. thaliana.}

Using the synthesized cDNA as template, four target gene specific fragments were amplified by PCR with high fidelity, and the RNAi fragments with the same length were obtained (Figure 3E). Then, the target genes were recombined with the overexpression vector pCAMBIA1300-35s (OPR-OE), positive strains were screened. After sequencing, the overexpression vectors pCAMBIA1300-35s-OPR1 (OPR1-OE), pCAMBIA1300-35s-OPR2 (OPR2-OE), pCAMBIA1300-35s-OPR3 (OPR3-OE), and pCAMBIA1300-35s-OPR4 (OPR4-OE) were obtained (Figure 4A-B).

The RNAi fragment was recombined with the RNAi vector pCAMBIA1300-RNAi (OPRi) and the positive strains were screened. After sequencing, the RNAi vectors pCAMBIA1300-RNAi-OPR1 (OPR1i), pCAMBIA1300-RNAi-OPR2 (OPR2i), pCAMBIA1300-RNAi-OPR3 (OPR3i), and pCAMBIA1300-RNAi-OPR4 (OPR4i) were obtained (Figure 4C).

The recombinant vector was transformed into $A$. thaliana and the obtained $A$. thaliana was detected. The $\mathrm{T}_{1}$ transgenic $A$. thaliana seeds were screened using hygromycin (Figure $\mathbf{5 A}$ ) and the results of hygromycin primer identification (Figure 5B) showed that each copy of $A$. thaliana OPR had been successfully transformed, and the target plasmid T-DNA had been inserted into the genome of $A$. thaliana.

\section{Analysis of fatty acid composition and fatty acid content}

The transformation methods in A. thaliana, reference Clough and Bent (1998) [35]. fatty acid composition was detected by gas chromatography [36]. we obtained fatty acid composition results of the $T_{1}$ and $T_{2}$ generations. Fatty acid composition of $A$. thaliana T-DNA insertion lines in table 5 , and transformation materials fatty acid composition in the contrast T1/T2. The contents of oleic acid and stearic acid in OPR1i were significantly increased and the LA content decreased significantly; OPR1-OE will lead to a significant increase in palmitic acid and LA content; OPR2i significantly increased stearic acid content and decreased LA content; and OPR2-OE increased LA content.

The LA content in OPR3i decreased significantly; OPR3-OE significantly increased LA content; OPR4i significantly decreased LA content; and OPR4-OE increased LA content significantly.

Each copy of OPR-OE increased LA content, with an average increase of $12.56 \%$ in $\mathrm{T}_{1}$ generation and $7.185 \%$ in $\mathrm{T}_{2}$ generation. Subsequently, LA content in OPRi gene was significantly decreased, with an average decrease of $5.98 \%$ in $\mathrm{T}_{1}$ generation and $0.86 \%$ in $\mathrm{T}_{2}$ generation.

As shown in Table 5, oleic, linolenic, arachidonic, and erucic acids with the same variation trend as that of the fatty acid composition were selected for variance analysis. The results (Table 6) showed that the linolenic acid content in OPR1i significantly increased, while OPR2i significantly increased the linolenic acid content. Both OPR3-OE and OPR4-OE affected the content of arachidonic acid, which decreased significantly. In addition, OPR4i had no significant effect on the arachidonic acid content.

\section{Discussion}

\section{miRNA expression and enrichment analysis}

miRNA is a type of sRNA that can regulate gene expression level and has an important regulatory effect on transcription. miRNAs have been found and reported in many plant species. In recent years, the number of known miRNAs has increased continually, such as $A$. thaliana [37] and Oryza sativa [38, 39]. $B$. napus $L$. has a relatively high genome size and complexity [33], and the number and function of miRNAs in $B$. napus $L$. have not been adequately studied; which suggests that many miRNAs have not yet been discovered, especially in seeds.

In this study, MiRNA libraries were constructed from self-pollinated seeds that were collected 20-35 d after pollination of rapeseed with high oleic acid content in the near-isogenic lines. Clean reads exhibited $87.45 \%$ (A) and $88.26 \%$ (B) homology with the referenced genome sequences (Table 1$)$. The small RNAs (24 nt) were most abundant in all the samples (Figure 1A). In addition, the clustering analysis results showed that three samples of high or low oleic acid contents were found in a cluster, revealing that these miRNAs might have similar biological functions (Figure 1B). Moreover, the above data indicated that the miRNA sequencing results in this study were of high quality and reliability, and can thus be used for further functional analysis. A total of 21 differentially expressed miRNAs were detected (Table 2, Supplemental Table 2), including 9 (42.86\%) up-regulated and 12 (57.14\%) down-regulated genes (Figure 1C). The present study provided a holistic view of HOAR immature seed miRNAs; the differential miRNAs and related putative target genes and their expressions obtained in this study can be utilized to study the molecular mechanism of fatty acids. To ensure the accuracy of the results, combination of RT-PCR technologies to further verify. Genes related to Cd stress, such as BNPCS1, BNGSTU12, and BNGSTU5, have previously been discovered using GO and KEGG pathways [40]. A total of 13 differentially expressed miRNAs were confirmed by RT-PCR, and a hypothetical model of cadmium response mechanism in Brassica napus was proposed on this basis [41].

In our study, Bna-miR156b>c>g may be involved in fatty acid metabolism. A total of 20 pathways were enriched by KEGG pathway, involving 36 target genes, of which 15 may be involved in the regulation of fatty acid metabolism; the reliability of the results was verified using the RT-PCR analysis. This result provided a basis for subsequent functional verification.

\section{Multi copy phenomenon of OPR genes}


We found that $O P R$ gene has four copies in rapeseed, with $O P R 1$ and $O P R 4$ located in the $C$ genome and $O P R 2$ and $O P R 3$ located in the A genome. The $O P R$ gene has been identified in several species and there are often multiple copies. Three OPRs were found in A. thaliana and tomato [42], 6 in peas [43], and 8 in corn [44]. Meanwhile, rice comprised 13 OPRs [45] and wheat had 48 OPRs [46]. Multi-copy genes are ubiquitous in plants and play an important role in maintaining plant genetic stability; however, they have hindered molecular breeding research. The loss of a few copies of gene function often does not cause phenotypic changes, and the probability of simultaneous mutation of multiple copy sites is too low to create a gene family or multiple copies of genes change simultaneously [47]. Rapeseed is an allotetraploid with many multi-copy genes. Conventional molecular breeding research methods are difficult to obtain phenotypic multi-copy gene mutants. Handa found that the main DNA sequence of the protein coding region was highly conserved between rapeseed and $A$. thaliana [48]. Transformation with $A$. thaliana as a receptor is helpful to study the function of multi-copy genes in rapeseed. In this study, we found four copies of $O P R$ gene in rapeseed. Based on these multi-copy genes, we preliminarily transformed a single copy in $A$. thaliana. In the future, we will consider transferring multiple copies simultaneously to study the functionality of $O P R$ genes in depth.

\section{Regulation function of OPR genes to fatty acid}

In this study, we found that OPR genes may affect the metabolism of linoleic acid and each copy was transferred separately into $A$. thaliana. The LA content of OPR-OE transgenic plants was significantly increased $\left(T_{1} 12.56 \%, T_{2} 7.185 \%\right)$, while the LA content of OPRi transgenic plants was significantly decreased $\left(\mathrm{T}_{1} 5.98 \%, \mathrm{~T}_{2}\right.$ 0.86\%). These results have rarely been reported before. However, it has been described that the CIOPR genes, particularly CIOPR2 and CIOPR4, significantly upregulated by exogenous jasmonic acid, salicylic acid, and ethylene treatments in watermelon [49]. Virus-induced gene silencing (VIGS) analysis suggested that knockdown of GhOPR9 could increase the susceptibility of cotton to V. dahliae infection [50]. OPR gene was cloned from Oryza sativa; the overexpression of $O P R$ genes was found to enhance the stress resistance of tobacco to heavy metal $\mathrm{Cd}^{2+}$ [51]. Previous studies concluded that $O P R$ genes were widely involved in abiotic stress processes [52]. In addition, OPR genes involved in fatty acid $\beta$ oxidation, cilinolenic acid reduction, and the octadecanoic acid metabolic pathway [53]. However, there were few reports on OPR genes regulating OA, LA, or saturated fatty acid synthesis. In our study, we found that $O P R$ genes directly affect the synthesis of linoleic acid and indirectly affect the content of other fatty acids (Figure 6), which is consistent with the theoretical pathway wherein $O P R$ genes regulate JA synthesis using alpha-linolenic acid $(18: 3)[53,54]$. Thus showing a greater correlation between $O P R$ genes and linoleic acid content and not a-linolenic acid (ALA).

A. thaliana and rapeseed are both cruciferous plants and current studies have shown that their gene functions are basically the same, It is of practical significance to study in model plants [48]. We found the optimizing quality fatty acids in $A$. thaliana can be changed by regulating $O P R$ genes. Therefore, $O P R$ may be involved in regulating linoleic acid synthesis and improving fatty acid composition in rapeseed. This is the first study which discovered that the $O P R$ gene can regulate LA metabolism. Therefore, this study is a good reference for studies researching the molecular mechanism of linoleic acid synthesis and molecular breeding in rapeseed.

In this study, 20 pathways were enriched using the KEGG pathway through high-throughput sequencing, of which 15 may be involved in the regulation of fatty acid metabolism. The reliability of the results was verified by performing the RT-PCR analysis, which provided a basis for subsequent functional verification. We excavated a target gene $O P R$, bna-miR $156 b>c>g$, from rapeseed that may be related to fatty acid synthesis and identified the function of $O P R$ genes through transformation of $A$. thaliana. Importantly, OPR gene was transferred separately into $A$. thaliana. The LA content of OPR-OE transgenic plants significantly increased $\left(T_{1} 12.56 \%, T_{2} 7.185 \%\right)$, and the LA content of OPRi transgenic plants significantly decreased ( $\left.T_{1} 5.98 \%, T_{2} 0.86 \%\right)$. In addition, by performing a bioinformatics analysis, we found four copies of the OPR gene in the cytoplasm that were located on chromosomes A and C. In this study, by detecting the fatty acid content of different generations of transgenic $A$. thaliana, the four copies of $O P R$ gene that can directly affect LA content and indirectly affect other high quality fatty acids were discovered for the first time. These results can be used in breeding programs aimed at optimizing fatty acid profiles in rapeseed [55].

\section{Methods}

\section{Plant materials and growth conditions}

The near-isogenic rapeseed lines with high (81.4 \%) and low (56.2 \%) oleic acid contents were provided by Rapeseed Molecular Breeding of Hunan Agricultural University, the strain was originally cultivated by National Oil Improvement Center of Hunan Agricultural University. The materials exhibited stable traits and were planted in the experimental field of Hunan Agricultural University, China (Changsha, China) with standard agronomic methods [56]. The seeds 20 d after pollination were quickly frozen in liquid nitrogen and stored at $-80{ }^{\circ} \mathrm{C}$ for subsequent studies [57]. The sample treatment method adopted in this study is the same with our previous study [58].

The seeds of wild-type (WT) A. thaliana (ecotype: Columbia) were bought from Think Gene Biological Technology Co., LTD $₫ S h a n g h a i$, China. Plants were grown under greenhouse conditions: $24^{\circ} \mathrm{C}$ with a photoperiod of $18.5 \mathrm{~h}$-light/5.5 h-dark, with a light intensity of $6500 \mathrm{~lx}$.

\section{sRNA library construction and high throughput sequencing}

Total RNA was extracted from frozen seeds using the Trizol reagent (Sigma Aldrich, St. Louis, MO, USA), according to the manufacturer's instructions. The quality and quantity of the purified RNA were assessed using an Agilent 2100 Bioanalyzer (Agilent Technologies, Palo Alto, Santa Clara, USA) and RNA 6000 nanokit (Agilent Technologies, Palo Alto, Santa Clara, USA). sRNAs with lengths of 18-30 nt were separated and purified using 15\% denaturing polyacrylamide gel electrophoresis. Consequently, sRNAs fractions were ligated to the 5 ' lectrophoresters using T4 RNA ligase (Epicentre, America). The adapter-ligated fragments were then reverse transcribed and amplified by performing PCR with a pair of adapter complementary primers. These PCR products were purified and sequenced using IlluminaHiseq XTEN (Illumina, USA). Construction of the sRNA libraries and deep sequencing were carried out by Oebiotech Genomics (Shanghai, China). 
Clean reads were generated after eliminating the low-quality reads, poly As, reads smaller than $18 \mathrm{nt}$, and gener adaptor contaminants and subsequently inserting nulls. Using bowtie software [59], the clean reads were aligned against the NCBI Gen Bank [60], B. napus oilseed genome [33], and Rfam databases (version 10.0). Reads annotated into the noncoding RNA categories, including rRNA, tRNA, snRNA, and snoRNA were filtered. The remaining sRNA sequences were aligned against the mi RBase21.0 [61]. The nearly matched sequences (less than two mismatches) were considered to be the known miRNAs. The unannotated sRNAs were further analyzed to predict the novel miRNAs using the Mirdeep2 software. The secondary structures of premiRNAs were also predicted using the RNAfold software.

To reveal the continuous changes in expression of miRNAs during the biosynthesis process, the variation in expression was analyzed in immature seed libraries of high oleic acid rapeseeds (HOAR). The frequency of miRNAs was normalized as transcripts per million (TPM) for further analysis. In addition, miRNAs were assessed using the negative binomial distribution test, with $\mathrm{P}<0.05$ and absolute value of log2 (treatment/control) $>1.5$ being considered as differentially expressed. Moreover, the similarity between samples was investigated by the clustering method. The Blast $2 \mathrm{GO}$ software with default parameters was applied to determine the functional annotation and categorization of the target genes [62]. The KEGG (Kyoto Encyclopedia of Genes and Genomes) and InterPro databases were also searched with an evalue of $1 \mathrm{e}^{-10}$.

\section{Real time quantitative polymerase chain reaction (RT-PCR) validation of differentially expressed miRNAs}

To validate the expression of differentially expressed miRNAs, all annotated miRNAs were selected for RT-PCR validation using the poly (T) adaptor RT-PCR method [63]. The RT-PCR amplifications were performed according to an established procedure [64]. 5S rRNA was used as an internal reference gene of miRNA and two primers were used: F: 5'-CTCGGCAACGGATATCTCG-3' and R: 5'-CTAATGGCTTGGGGCG-3'. The internal reference gene of the miRNA target gene was UBC9 and two primers were used: F: 5'-TCCATCCGACAGCCCTTACTCT-3' and R: 5'-ACACTTTGGTCCTAAAAGCCACC-3'. All reactions were performed in triplicate. The RT-qPCR was conducted on the Step One Plus RT-PCR System ( $A B I$, America). The relative expression was calculated using the 2- $\triangle C T$ method [65]. Statistical analyses consisted of analysis of variance and Fisher'spost-hoc tests. A p-value $<0.05$ was considered statistically significant. Details of the RT-PCR primers were provided in Table 2.

\section{Cloning of $O P R$ genes in rapeseed and bioinformatic analysis}

Four copies of OPR genes were found using miRNA sequencing homologous cloning. Total RNA was extracted from the rapeseed leaf samples using the CTAB method adopted by Niu et al. (2018) [66], with minor modifications. cDNA was produced by implementing reverse transcription, which was followed by PCR amplification (Table 7). According to each copy sequence of $O P R$, the physical and chemical properties of corresponding proteins were analyzed by using online websites such as the ExPASY-Protparam Tool and modifying the methods described by Li et al. $(2019)$ and Sun et al. $(2016)[67,68]$.

Bioinformatic analysis of OPRs: The ExPASy-ProtParam tool website (https://web.expasy.org/protparam/) predicted the primary structure of the protein. The subcellular localization of OPR proteins were performed using the PredictProtein SOPMA website (http://www.predictedprotein.org/). TMHMM Server, v. 2.0 (http://www.cbs.dtu.dk/services/TMHMM/) was usedto analyze the transmembrane helix region of proteins. The SOPMA website (https://npsaprabi.ibcp.fr/cgi-bin/npsa_automation.pl?Page=npsa_sopma.html) predicted the secondary protein structure. The tertiary structure model of each copy of OPR protein was constructed using the SWISS-MODEL website (https://swissmodel.expasy.org/).

\section{Vector construction and transformation of $A$. thaliana}

Specific RNAi primer (Table 8) cDNA was used as a template. The base before the 5 '-end enzyme digestion site was used for the construction of recombinant plasmids (the same below), according to the method adopted by Li et al. (2021) with minor modifications [69]. The cloned OPR sequence was digested with BamHI and SalI (Table 7) and recombinant with pCAMBIA1300-35s vector (Kangyan Corporation, China) to construct pCAMBIA1300-35s-OPR vector.

Similarly, the pCAMBIA1300-RNAi-OPR vector (Kangyan Corporation, China) was reconstructed using a double digestion process in vitro (Table 8) by following the methods of Yang et al. (2012) and Qu et al. (2017) with minor modifications [29, 6]. pCAMBIA1300-35s-OPR and pCAMBIA1300-RNAi-OPR vectors were transformed into $A$. thaliana because of inflorescence infection to explore the function of each copy by using the inflorescence infection method of Clough and Bent (1998) [35], with minor modifications.

\section{Fatty acid detection and statistical methods}

Using Agilent Technologies 7890B gas chromatograph, MSD detector, 5977A chromatographic workstation, and DB-23 capillary chromatographic column, sample size $1 \mu$, Heating procedure: initial holding time $10 \mathrm{~min}$, initial temperature $180^{\circ} \mathrm{C}, 20^{\circ} \mathrm{C} / \mathrm{min}$, rising to $250^{\circ} \mathrm{C}$, according to the fatty acid detection method of Mao et al. (2020) [36], with minor modifications.

Microsoft Excel 2010 was used to collate the data and one-way analysis of variance was used for analysis [70].

\section{Abbreviations}

RT-PCR: Quantitative Real-time PCR; OPR: 12-oxo-phytodienoic acid reductase; OPR-OE: OPR Over-Expression strain; OPRi: OPRi RNA-interference strain; LA: Linoleic acid; ALA: a-linolenic acid; GLA: $Y$-linolenic acid.

\section{Declarations}


Availability of data and materials

Data of RNA-seq in this study is available in NCBI with accession number PRJNA760803 that are publicly accessible at

https://www.ncbi.nlm.nih.gov/sra/PRJNA760803.

\section{Acknowledgements}

We are highly thankful to Xiaogang Lv (Chinese Academy of Agricultural Sciences) for her help in writing assays.

\section{Authors' Contributions}

ZQ Z and MB L designed the experiments, analyzed the data, M T and DZ P performed the experiments and wrote the manuscript, Q C and $\mathrm{J} N$ performed the bioinformatics analysis. All authors read and approved of the manuscript.

\section{Funding}

The authors gratefully acknowledge the financial support by the Natural Science Foundation of Changsha (kq2007015), National Transgenic Research Projects of China(2018ZX08020001), and the Natural Science Foundation of China (31201240).

\section{Ethics declarations}

\section{Ethics approval and consent to participate}

Not applicable.

\section{Consent for publication}

Not applicable.

\section{Competing interests}

The authors declare that they have no competing interests.

\section{Author details}

1 College of Agronomy, Hunan Agricultural University, Changsha, Hunan 410128, China

2 Institute of Bast Fiber Crops, Chinese Academy of Agricultural Sciences, Changsha, Hunan 410205, China

\section{References}

1. Song JM, Guan Z, Hu J, Guo C, Yang Z, Wang S, et al. Eight high-quality genomes reveal pan-genome architecture and ecotype differentiation of Brassica napus. Nat Plants. 2020; 6: 34-45.

2. Liu J, Hua W, Hu Z, Yang H, Zhang L, Li R, et al. Natural variation in ARF18 gene simultaneously affects seed weight and silique length in polyploid rapeseed. Proc Natl Acad Sci U S A. 2015; 112: E5123-E5132.

3. Aram S, Weisany W, Daliri MS, and Mirkalaie SP. Physiology, and Fatty Acid Profile of Canola (Brassica napus L.) under Agronomic Management Practices (Direct Seeding and Transplanting) and Zinc Foliar Application. Journal of Soil Science and Plant Nutrition (prepublish). 2021; 21: 1735-1744.

4. Pham AT, Shannon JG. and Bilyeu, KD. Combinations of mutant FAD2 and FAD3 genes to produce high oleic acid and low linolenic acid soybean oil. Theor Appl Genet. 2012; 125: 503-515.

5. Koletzko B, Reischl E, Tanjung C, Gonzalez-Casanova I, Ramakrishnan U, Meldrum S, et al.. FADS1 and FADS2 Polymorphisms Modulate Fatty Acid Metabolism and Dietary Impact on Health. Annu Rev Nutr. 2019; 21: 21-44.

6. Qu C, Jia L, Fu F, Zhao H, Lu K, Wei L, et al.. Genome-wide association mapping and Identification of candidate genes for fatty acid composition in Brassica napus L. using SNP markers. BMC Genomics. 2017; 18: 377.

7. Noemi RL, Sayanova O, Napier JA, and Haslam RP. Metabolic engineering of the omega-3 long chain polyunsaturated fatty acid biosynthetic pathway into transgenic plants. J Exp Bot, 2012; 63: 2397-2410.

8. Carrington JC, and Ambros V. Role of microRNAs in plant and animal development. Science (New York, N. Y.), 2003; 301: 336-8.

9. Zhou B, Fan P, Li Y, Yan H, and Xu Q. Exploring miRNAs involved in blue/UV-A light response in Brassica rapa reveals special regulatory mode during seedling development. BMC plant biology, 2016; 16: 111.

10. Dhandapani V, Ramchiary N, Paul P, Kim J, Choi S H, Lee J, et al. Identification of potential microRNAs and their targets in Brassica rapa L. Molecules and cells. 2011; 32: 21-37.

11. Jiao Y, Wang Y, Xue D, Wang J, Yan M, Liu G, et al. Regulation of OsSPL14 by OsmiR156 defines ideal plant architecture in rice. Nature genetics, 2010; 42 : 541-4.

12. Yan Z, Hossain MS, Oswaldo VL, Hoang NT, Zhai J, and Wang J.. Identification and functional characterization of soybean root hair micrornas expressed in response to bradyrhizobium japonicum infection. Plant Biotechnology Journal. 2015; 14. 
13. Bhardwaj AR, Joshi G, Pandey R, Kukreja B, Goel S, Jagannath A, et al. A genome-wide perspective of miRNAome in response to high temperature, salinity and drought stresses in Brassica juncea (Czern) L. PloS one, 2014; 9: e92456.

14. Kantar M, Lucas SJ, and Budak H. miRNA expression patterns of Triticum dicoccoides in response to shock drought stress. Planta, 2011; 233 : 471-84.

15. Shen J, Xie K, and Xiong L. Global expression profiling of rice microRNAs by one-tube stem-loop reverse transcription quantitative PCR revealed important roles of microRNAs in abiotic stress responses. Molecular genetics and genomics: MGG. 2010; 284: 477-88.

16. Verma SS, Rahman MH, Deyholos MK, Basu U, and Kav NN. Differential expression of miRNAs in Brassica napus root following infection with Plasmodiophora brassicae. PloS one. 2014; 9: e86648.

17. Xu M Y, Dong Y, Zhang QX, Zhang L, Luo YZ, Sun J, et al. Identification of miRNAs and their targets from Brassica napus by high-throughput sequencing and degradome analysis. BMC genomics, 2012; 13: 421.

18. Zhou Z S, Song J B, and Yang Z M. Genome-wide identification of Brassica napus microRNAs and their targets in response to cadmium. Journal of experimental botany, 2012; 63: 4597-613.

19. Huang D, Koh C, Feurtado J A, Tsang E W, and Cutler A J. MicroRNAs and their putative targets in Brassica napus seed maturation. BMC genomics. 2013; 14: 140 .

20. Huang Y, Chen L, Wang L, Vijayan K, Phan S, Liu Z, et al. Probing the endosperm gene expression landscape in Brassica napus. BMC genomics, 2009; 10: 256.

21. Zhao YT, Wang M, Fu SX, Yang WC, Qi CK, and Wang XJ. Small RNA profiling in two Brassica napus cultivars identifies microRNAs with oil productionand development-correlated expression and new small RNA classes. Plant physiology, 2012; 158: 813-23.

22. Korbes AP, Machado RD, Guzman F, Almerao MP, Oliveira LF, Loss-Morais G, et al. Identifying conserved and novel microRNAs in developing seeds of Brassica napus using deep sequencing. PloS one, 2012; 7: e50663.

23. Wang Z, Qiao Y, Zhang J, Shi W, and Zhang J. Genome wide identification of microRNAs involved in fatty acid and lipid metabolism of Brassica napus by small RNA and degradome sequencing. Gene, 2017; 619: 61-70.

24. Bocianowski J, Mikołajczyk K, and Bartkowiak-Broda I. Determination of fatty acid composition in seed oil of rapeseed (Brassica napus L.) by mutated alleles of the FAD3 desaturase genes. Journal of applied genetics, 2012; 53, 27-30.

25. Peng D, Zhang L, Tan XF, and Zhou B. Increasing seed oil content and altering oil quality of Brassica napus L. by over-expression of diacylglycerol acyltransferase 1 (SsDGAT1) from Sapium sebiferum (L.) Roxb. Molecular Breeding, 2016; 36:136.

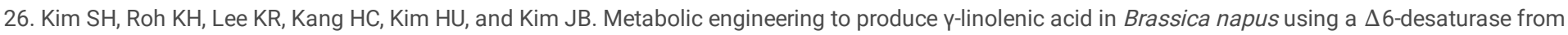
pike eel. Plant Biotechnology Reports, 2016; 10: 1-7.

27. Dhakate P, Tyagi S, Singh A, and Singh A. Functional characterization of a novel Brassica LEAFY homolog from Indian mustard: Expression pattern and gain-of-function studies. Plant Sci, 2017; 258: 29-44.

28. Rahman H, Singer SD, and Weselake RJ. Development of low-linolenic acid Brassica oleracea lines through seed mutagenesis and molecular characterization of mutants. Theor Appl Genet, 2013; 126: 1587-1598.

29. Yang Q, Fan C, Guo Z, Qin J, Wu J, Li Q, et al. Identification of FAD2 and FAD3 genes in Brassica napus genome and development of allele-specific markers for high oleic and low linolenic acid contents. Theor App/ Genet, 2012; 125: 715-729.

30. Guan M, Huang X, Xiao Z, Jia L, Wang S, Zhu M, et al. Association Mapping Analysis of Fatty Acid Content in Different Ecotypic Rapeseed Using mrMLM. Front Plant Sci, 2019; 9: 1872.

31. Zhao Q, Wu J, Cai G, Yang Q, Shahid M, Fan C, et al. A novel quantitative trait locus on chromosome A9 controlling oleic acid content in Brassica napus. Plant Biotechnol J, 2019; 17: 2313-2324.

32. Javed N, Geng JF, Tahir M, McVetty PBE, Li G, and Duncan RW. Identification of qtl influencing seed oil content, fatty acid profile and days to flowering in Brassica napus L. EUPHYTICA, 2016; 207: 191-211.

33. Chalhoub B, Denoeud F, Liu S, Parkin I, Tang H, Wang X, et al. Plant genetics. Early allopolyploid evolution in the post-Neolithic Brassica napus oilseed genome. Science, 2014; 345: 950-953.

34. Fox KM, and Karplus PA. Old yellow enzyme at 2 A resolution: overall structure, ligand binding, and comparison with related flavoproteins. Structure, 1994; 2: $1089-1105$.

35. Clough SJ, and Bent AF. Floral dip: a simplified method for Agrobacterium-mediated transformation of Arabidopsis thaliana. The Plant Journal, 1998; 16: 735-743.

36. Mao X, Chen W, Huyan Z, Sherazi STH, and Yu X. Impact of linolenic acid on oxidative stability of rapeseed oils. J Food Sci Technol, 2020; 57: 31843192.

37. Fahlgren N, Howell MD, Kasschau KD, Chapman EJ, Sullivan CM, Cumbie JS, et al. High-throughput equencing of Arabidopsis microRNAs: evidence for frequent birth and death of MIRNA genes. PLoS One, 2007; 2: e219.

38. Wu L, Zhang Q, Zhou H, Ni F, Wu X, and Qi Y. Rice MicroRNA effector complexes and targets. Plant Cell. 2009; 21: 3421-3435.

39. Liu Q. Novel miRNAs in the control of arsenite levels in rice. Funct Integr Genomics, 2012; 12, 649-658.

40. Ding Y, Jian H, Wang T, Di F, Wang J, Li J, et al. Screening of candidate gene responses to cadmium stress by RNA sequencing in oilseed rape (Brassica napus L.). Environ Sci Pollut Res Int. 2018; 25: 32433-32446.

41. Jian H, Yang B, Zhang A, Ma J, Ding Y, Chen Z, et al. Genome-Wide Identification of MicroRNAs in Response to Cadmium Stress in Oilseed Rape (Brassica napus L.) Using High-Throughput Sequencing. Int J Mol Sci. 2018; 19: 1431. 
42. Breithaupt C, Kurzbauer R, Lilie H, Schaller A, Strassner J, Huber R, et al. Crystal structure of 12-oxophytodienoate reductase 3 from tomato: self-inhibition by dimerization. Proceedings of the National Academy of Sciences of the United States of America, 2006; 103: 14337-14342.

43. Matsui H, Nakamura G, Ishiga Y, Toshima H, Inagaki Y, Toyoda K, et al. Structure and expression of 12-oxophytodienoate reductase (subgroup I) genes in pea, and characterization of the oxidoreductase activities of their recombinant products. Molecular Genetics and Genomics, $2004 ; 271: 1-10$.

44. Zhang J, Simmons C, Yalpani N, Crane V, Wilkinson H, and Kolomiets M. Genomic analysis of the 12-oxo-phytodienoic acid reductase gene family of Zea mays. Plant Molecular Biology, 2005; 59: 323-343.

45. Li W, Zhou F, Liu B, Feng D, He Y, Qi K, et al. Comparative characterization, expression pattern and function analysis of the 12-oxo-phytodienoic acid reductase gene family in rice, Plant Cell Reports, 2011; 30: 981-995.

46. Mou, Y., Liu, Y., Tian, S., Guo, Q., Wang, C., and Wen, S. (2019). Genome-Wide Identification and Characterization of the OPR Gene Family in Wheat (Triticum aestivum L.). International Journal of Molecular Sciences, 20, 1914. doi: 10.3390/ijms20081914

47. Wang L, Zheng J, Luo Y, Xu T, Zhang Q, Zhang L, et al. Construction of a genomewide RNAi mutant library in rice. Plant Biotechnol J, 2013 ; 11: $997-1005$.

48. Handa $\mathrm{H}$. The complete nucleotide sequence and RNA editing content of the mitochondrial genome of rapeseed (Brassica napus $L$.): comparative analysis of the mitochondrial genomes of rapeseed and Arabidopsis thaliana. Nucleic Acids Res, 2003; 31: 5907-5916.v.

49. Guang Y, Luo S, Ahammed GJ, Xiao X, Li J, Zhou Y, et al. The OPR gene family in watermelon: Genome-wide identification and expression profiling under hormone treatments and root-knot nematode infection. Plant Biol (Stuttg). Plant Biology, 2021; 23: Suppl 1:80-88.

50. Liu SC, Sun RB, Zhang XJ, Feng ZL, Wei F, Zhao LH, et al. Genome-Wide Analysis of OPR Family Genes in Cotton Identified a Role for GhOPR9 in Verticillium dahliae Resistance. Genes, 2020; 11: 1134.

51. Xia F, Dai T, Yao XZ, and Lv L. Cloning of Oryza sativa OPR Gene and Its Cadmium Resistance in Tobacco. Seed. 2020; 39 : 53-58.

52. You SH, Tan P, Wu WJ, Wu Z, Chen Y P, Yi HW, et al. Genome-wide Identification of OPR Family Genes and the Expression of theseGenes in Response to Heavy Metal Stress in Grapevine(Vitis vinifera L.). Genomics and Applied Biology. 2020; 4: 1-14.

https://kns.cnki.net/kcms/detail/45.1369.q.20201209.0854.002.html

53. Turner JG, Ellis C, and Devoto A. The jasmonate signal pathway. Plant Cell. 2002: 14 Suppl(Suppl): S153-64.

54. Weber H, Vick BA, and Farmer EE. Dinor-oxo-phytodi-enoic acid: A new hexadecanoid signal in the jasmonate family. Proc. Natl Acad Sci USA, 1997; 94, 10473-10478.

55. Qu C, Jia L, Fu F, Zhao H, Lu K, Wei L, et al. Genome-wide association mapping and Identification of candidate genes for fatty acid composition in Brassica napus L. using SNP markers. BMC Genomics. 2017; 18: 377.

56. Wang Y, Yang Q, Zhang Z, Xiao G, Guan C, Liu Z, et al. iTRAQ-based quantitative proteomics analysis of immature rapeseed of high oleic acid nearisogenic lines. Molecular Breeding, 2018; 38: 2.

57. Qi P, Yan H, Ran W, Yuan Z, Chunyun G, Ying R, et al. Simultaneous silencing of FAD2 and FAE1 genes affects both oleic acid and erucic acid contents in Brassica napus seeds. Plant Cell Rep. 2009; 29: 317-325.

58. Zhang ZQ, Tan M, Xiao G, Wu XM. and Guan CY. Comparative study of different oleic acid content of rapeseed. Journal of Biology, 2015; 32 : 20-24. https://kns.cnki.net/kcms/detail/detail.aspx?FileName=SWXZ201504006\&DbName=CJFQ2015

59. Langmead B, and Salzberg SL. Fast gapped-read alignment with Bowtie 2. Nature methods, 2012; 9: 357-359.

60. Benson DA, Karsch-Mizrachi I, Lipman DJ, Ostell J, and Sayers EW. GenBank. Nucleic acids research, 2011; 39 : D32-D37.

61. Griffiths-Jones S, Saini HK, Dongen S, and Enright AJ. miRBase: tools for microRNA genomics. Nucleic acids research, 2008; 36: D154-8.

62. Gotz S, Garcia-Gomez JM, Terol J, Williams TD, Nagaraj SH, Nueda MJ, et al. High-throughput functional annotation and data mining with the Blast2GO suite. Nucleic acids research, 2008; 36: 3420-3435.

63. Shi R, and Chiang VL. Facile means for quantifying microRNA expression by real-time PCR. BioTechniques, 2005; 39: 519-525.

64. Sun Y, Qiu Y, Duan M, Wang J, Zhang X, Wang H, et al. Identification of anthocyanin biosynthesis related microRNAs in a distinctive Chinese radish (Raphanus sativus L.) by high-throughput sequencing. Molecular genetics and genomics: Molecular Genetics and Genomics. 2017; 292: 215-229.

65. Livak KJ, and Schmittgen TD. Analysis of relative gene expression data using real-time quantitative PCR and the 2(-Delta Delta C(T)) Method. Methods, 2001; 25: 402-408.

66. Niu J, Cao D, Li H, Xue H, Chen L, Liu B, and Cao S. Quantitative proteomics of pomegranate varieties with contrast-ing seed hardness during seed development stages. Trees Genet. Genome, 2018; 14: 14-25.

67. Li M, Wang R, Liang Z, Wu X, and Wang J. Genome-wide identification and analysis of the EIN3/EIL gene family in allotetraploid Brassica napus reveal its potential advantages during polyploidization. BMC Plant Biol, 2019; 19: 110.

68. Sun R, Gao L, Yu X, Zheng Y, Li D, and Wang X. Identification of a $\Delta 12$ fatty acid desaturase from oil palm (Elaeis guineensis Jacq.) involved in the biosynthesis of linoleic acid by heterologous expression in Saccharomyces cerevisiae. Gene, 2016; 591: 21-26.

69. Li YL, Yu YK, Zhu KM, Ding LN, Wang Z, Yang YH, et al. Down-regulation of MANNANASE7 gene in Brassica napus L. enhances silique dehiscenceresistance. Plant Cell Rep. 2021; 40: 361-374.

70. Waalen W, Overgaard SI, Assveen M, Eltun R, and Gusta LV. Winter survival of winter rapeseed and winter turnip rapeseed in field trials, as explained by ppls regression. European Journal of Agronomy, 2013; 51: 81-90.

\section{Tables}

Table 1 Statistics of sRNA sequences 


\begin{tabular}{|c|c|c|c|c|c|c|c|c|c|}
\hline & & $\mathrm{A} 1$ & $\mathrm{~A} 2$ & A3 & A mean value & B1 & B2 & B3 & $B$ mean value \\
\hline \multicolumn{2}{|l|}{ raw reads } & $3 \mathrm{E}+07$ & $2 \mathrm{E}+07$ & $1.8 \mathrm{E}+07$ & 22744964 & $2.6 \mathrm{E}+07$ & $2.4 \mathrm{E}+07$ & $2.8 \mathrm{E}+07$ & 26060122 \\
\hline \multicolumn{2}{|l|}{ clean reads } & 2.7E+07 & $1.9 \mathrm{E}+07$ & $1.7 \mathrm{E}+07$ & 20912776 & $2.5 \mathrm{E}+07$ & $2.1 \mathrm{E}+07$ & $2.5 \mathrm{E}+07$ & 23710938 \\
\hline \multicolumn{2}{|l|}{ uniq reads } & 4723178 & 3183059 & 3150216 & 3685484 & 4291822 & 3249172 & 3403565 & 3648186 \\
\hline \multicolumn{2}{|c|}{ reference genome matches } & $87.39 \%$ & $87.52 \%$ & $87.44 \%$ & $87.45 \%$ & $88.61 \%$ & $88.19 \%$ & $87.99 \%$ & $88.26 \%$ \\
\hline \multirow[t]{7}{*}{ Annotation type } & rRNA & $2.84 \%$ & $2.93 \%$ & $2.64 \%$ & $2.80 \%$ & $3.20 \%$ & $4.44 \%$ & $4.40 \%$ & $4.01 \%$ \\
\hline & tRNA & $32.77 \%$ & $38.46 \%$ & $32.80 \%$ & $34.68 \%$ & $29.42 \%$ & $43.11 \%$ & $47.02 \%$ & $39.85 \%$ \\
\hline & snRNA & $0.63 \%$ & $0.66 \%$ & $0.57 \%$ & $0.62 \%$ & $0.51 \%$ & $0.70 \%$ & $0.72 \%$ & $0.64 \%$ \\
\hline & Cis reg & $0.09 \%$ & $0.09 \%$ & $0.09 \%$ & $0.09 \%$ & $0.10 \%$ & $0.10 \%$ & $0.10 \%$ & $0.10 \%$ \\
\hline & others & $0.28 \%$ & $0.27 \%$ & $0.26 \%$ & $0.27 \%$ & $0.30 \%$ & $0.34 \%$ & $0.34 \%$ & $0.33 \%$ \\
\hline & gene & $0.40 \%$ & $0.40 \%$ & $0.37 \%$ & $0.39 \%$ & $0.34 \%$ & $0.49 \%$ & $0.52 \%$ & $0.45 \%$ \\
\hline & repeat & $2.23 \%$ & $2.52 \%$ & $2.03 \%$ & $2.26 \%$ & $2.55 \%$ & $3.78 \%$ & $3.97 \%$ & $3.43 \%$ \\
\hline \multicolumn{2}{|l|}{ Aligned reads } & $0.60 \%$ & $0.45 \%$ & $0.51 \%$ & $0.52 \%$ & $0.64 \%$ & $0.42 \%$ & $0.43 \%$ & $0.50 \%$ \\
\hline \multicolumn{2}{|c|}{ Aligned know miRNA } & 39 & 38 & 39 & 38.67 & 36 & 35 & 37 & 36 \\
\hline
\end{tabular}

Note: A: Low oleic acid rapeseed materials; B: High oleic acid rapeseed materials

Table 2 Primers for real time PCR analysis of miRNA 


\begin{tabular}{|c|c|}
\hline miRNA name & Primer Sequence \\
\hline NC_027757.1_266 & TGCCTGGCTCCCTGTATACCA \\
\hline NC_027760.1_5272 & TTGGAGGACTGGTGATGAAAAC \\
\hline NC_027760.1_5272* & TTGTAACAGCTTTTAGTCCTCTT \\
\hline NC_027761.1_6665 & ATACTTAGAGCCTTATTACGCCT \\
\hline NC_027768.1_15573 & ACCTTGTTTTGGTCGGACGAG \\
\hline NC_027769.1_17408 & CAGTTTTGTAAGTTCTGTCCAG \\
\hline NC_027769.1_17408* & GGTTGTTACTTATACGGCTATA \\
\hline NC_027772.1_21433 & CACAATCGCCCTTGAAGCTG \\
\hline NC_027774.1_24533 & CGAGTGTGAAGAATGCGGCG \\
\hline NC_027774.1_24533* & GATCCTTCTCGAGAAACTGGC \\
\hline NW_013650328.1_26640* & CTTTGCCTATCGTTTGGAAAAG \\
\hline bna-miR156a & TGACAGAAGAGAGTGAGCACA \\
\hline bna-miR156b>bna-miR156c>bna-miR156g & TTGACAGAAGATAGAGAGCAC \\
\hline bna-miR160a>bna-miR160b>bna-miR160c>bna-miR160d & TGCCTGGCTCCCTGTATGC \\
\hline bna-miR162a & TCGATAAACCTGTGCATCCAG \\
\hline bna-miR166f & TCGGACCAGGCTTCATCCC \\
\hline bna-miR167a>bna-miR167b & TGAAGCTGCCAGCATGATCTAA \\
\hline bna-miR169m & TGAGCCAAAGATGACTTGCCG \\
\hline bna-miR172d & AGAATCTTGATGATGCTGCAG \\
\hline bna-miR396a & TTCCACAGCTTTCTTGAACTT \\
\hline bna-miR824 & TAGACCATTTGTGAGAAGGGA \\
\hline
\end{tabular}

Table 3. TPM values of 21 differential miRNAs in Samples 


\begin{tabular}{|c|c|c|c|c|c|c|c|c|}
\hline miRNA_id & A1 TPM & A2 TPM & A3 TPM & $\begin{array}{l}\text { A TPM mean } \\
\text { values }\end{array}$ & B1_TPM & B1_TPM & B1_TPM & $\begin{array}{l}\text { B TPM m } \\
\text { values }\end{array}$ \\
\hline NC_027757.1_266 & 39.78041213 & 89.29803626 & 28.94628294 & 52.67491044 & 66.49508328 & 103.5718478 & 135.4255601 & 101.8308 \\
\hline NC_027760.1_5272 & 322.2213382 & 430.2541747 & 274.9896879 & 342.4884003 & 132.9901666 & 165.7149565 & 117.7613566 & 138.8221 \\
\hline NC_027760.1_5272* & 879.147108 & 1095.930445 & 817.7324929 & 930.9366819 & 434.173779 & 393.5730216 & 312.067595 & 379.9381 \\
\hline NC_027761.1_6665 & 1996.976689 & 2256.804916 & 2330.175776 & 2194.65246 & 1384.662322 & 1277.386123 & 1165.83743 & 1275.961 \\
\hline NC_027768.1_15573 & 1272.973188 & 1493.712606 & 1389.421581 & 1385.369125 & 1721.049214 & 2092.151325 & 1937.174316 & 1916.791 \\
\hline NC_027769.1_17408 & 2784.628849 & 3547.56744 & 3046.596279 & 3126.264189 & 3809.777124 & 4439.779875 & 3450.407749 & 3899.988 \\
\hline NC_027769.1_17408* & 83.53886546 & 113.6520461 & 115.7851317 & 104.3253478 & 195.5737743 & 151.9053768 & 153.0897636 & 166.8563 \\
\hline NC_027772.1_21433 & 1241.148858 & 1542.420626 & 1425.604435 & 1403.057973 & 1975.295121 & 1898.817209 & 1789.97262 & 1888.028 \\
\hline NC_027774.1_24533 & 198.9020606 & 332.8381351 & 296.6994001 & 276.1465319 & 121.2557401 & 158.8101666 & 194.3062384 & 158.1240 \\
\hline NC_027774.1_24533* & 787.6521601 & 1152.756468 & 926.2810539 & 955.5632273 & 621.9246024 & 552.3831882 & 594.6948509 & 589.6675 \\
\hline NW_013650328.1_26640* & 27770.7057 & 26415.98272 & 39605.75163 & 31264.14669 & 16392.99377 & 19395.5547 & 14502.31107 & 16763.61 \\
\hline bna-miR156a & 1917.415864 & 1574.892639 & 1599.282132 & 1697.196879 & 1795.367248 & 2768.820731 & 2926.369712 & 2496.852 \\
\hline bna-miR156b>c>g & 1149.65391 & 1250.172508 & 1121.668464 & 1173.831627 & 1799.278724 & 2271.675862 & 2861.600966 & 2310.851 \\
\hline bna-miR160a $>b>c>d$ & 449.518657 & 552.0242241 & 383.5382489 & 461.69371 & 645.3934553 & 704.288565 & 677.1278005 & 675.6032 \\
\hline bna-miR162a & 83.53886546 & 138.006056 & 72.36570734 & 97.97020961 & 0 & 0 & 0 & 0 \\
\hline bna-miR166f & 76732.43695 & 89371.09828 & 71996.64223 & 79366.72582 & 52182.99447 & 49652.34383 & 50655.04755 & 50830.12 \\
\hline bna-miR167a>b & 3751.292863 & 3287.791335 & 3661.704791 & 3566.929663 & 2256.921356 & 2969.059637 & 3526.95263 & 2917.644 \\
\hline bna-miR169m & 15.91216485 & 24.35400989 & 21.7097122 & 20.65862898 & 0 & 0 & 0 & 0 \\
\hline bna-miR172d & 473.3869043 & 454.6081846 & 752.6033563 & 560.1994817 & 269.8918086 & 296.9059637 & 288.5153237 & 285.1043 \\
\hline bna-miR396a & 751.8497892 & 576.378234 & 723.6570734 & 683.9616989 & 340.2983674 & 428.0969709 & 577.0306474 & 448.4753 \\
\hline bna-miR824 & 700.1352534 & 681.9122769 & 549.9793758 & 644.0089687 & 907.4623129 & 1180.719065 & 1118.732888 & 1068.971 \\
\hline
\end{tabular}

Table 4 Primary and secondary structure analysis of each copy protein. 


\begin{tabular}{|c|c|c|c|c|c|}
\hline structure & Analysis & OPR1 & OPR2 & OPR3 & OPR4 \\
\hline \multirow{9}{*}{$\begin{array}{l}\text { Physical and } \\
\text { chemical properties } \\
\text { of primary } \\
\text { structures }\end{array}$} & $\begin{array}{l}\text { Number of amino } \\
\text { acids }\end{array}$ & 372 & 374 & 372 & 373 \\
\hline & Molecular weight & 41.4 & 41.57 & 41.32 & 41.28 \\
\hline & Theoretical pl & 5.55 & 6.01 & 5.88 & 6.22 \\
\hline & $\begin{array}{l}\text { Total number of } \\
\text { positively charged } \\
\text { residues(Arg + Lys) }\end{array}$ & 46 & 44 & 43 & 42 \\
\hline & $\begin{array}{l}\text { Total number of } \\
\text { negatively charged } \\
\text { residues(Asp + Glu) }\end{array}$ & 37 & 38 & 37 & 38 \\
\hline & Formula & $\mathrm{C}_{1844} \mathrm{H}_{2838} \mathrm{~N}_{508} \mathrm{O}_{550} \mathrm{~S}_{15}$ & $\mathrm{C}_{1844} \mathrm{H}_{2863} \mathrm{~N}_{511} \mathrm{O}_{554} \mathrm{~S}_{16}$ & $\mathrm{C}_{1843} \mathrm{H}_{2839} \mathrm{~N}_{509} \mathrm{O}_{546} \mathrm{~S}_{15}$ & $\mathrm{C}_{1835} \mathrm{H}_{2843} \mathrm{~N}_{509} \mathrm{O}_{546} \mathrm{~S}_{16}$ \\
\hline & Instability index & 38.82 & 35.76 & 39.65 & 38.57 \\
\hline & Aliphatic index & 75.27 & 75.64 & 75.27 & 75.6 \\
\hline & $\begin{array}{l}\text { Grand average of } \\
\text { hydropathicity } \\
\text { (GRAVY) }\end{array}$ & -0.355 & -0.359 & -0.343 & -0.325 \\
\hline \multirow[t]{5}{*}{ Secondary structure } & Alpha helix (Hh) & 31.18 & 31.55 & 31.18 & 30.56 \\
\hline & Beta bridge $(\mathrm{Bb})$ & 0 & 0 & 0 & 0 \\
\hline & Extended strand (Ee) & 12.63 & 12.03 & 12.63 & 12.87 \\
\hline & Beta turn (Tt) & 6.72 & 6.42 & 7.26 & 8.04 \\
\hline & Random coil (Cc) & 49.46 & 50 & 48.92 & 48.53 \\
\hline
\end{tabular}

Table 5 Analysis of fatty acid composition of $T_{1}$ and $T_{2}$ seeds 


\begin{tabular}{|c|c|c|c|c|c|c|c|c|c|}
\hline \multicolumn{3}{|c|}{ Strain } & \multicolumn{3}{|c|}{ Saturated fatty acids (\%) } & \multicolumn{4}{|c|}{ Unsaturated fatty acid (\%) } \\
\hline & & & Palmitic acid & Stearic acid & Total & Oleic acid & Linoleic acid & Linolenic acid & $\begin{array}{l}\text { Arachidonic } \\
\text { acid }\end{array}$ \\
\hline \multirow[t]{17}{*}{$\mathrm{T}_{1}$} & \multicolumn{2}{|c|}{ Contrast $\mathrm{T}_{1}$} & $7.851 \pm 0.37$ & $2.947 \pm 0.14$ & 10.798 & $15.145 \pm 3.51$ & $28.204 \pm 2.31$ & $19.115 \pm 1.53$ & $19.925 \pm 2.05$ \\
\hline & \multirow[t]{4}{*}{ OPR1 } & OPR1i & $6.8309 \pm 0.277$ & $3.3757 \pm 0.221$ & 10.2066 & $22.5651 \pm 2.401$ & $25.1403 \pm 1.838$ & $14.231 \pm 1.057$ & $18.7597 \pm 1.975$ \\
\hline & & $\begin{array}{l}\text { Increase } \\
\text { or } \\
\text { decrease }\end{array}$ & $-12.99 \%{ }^{* \star}$ & $14.55 \%{ }^{\star *}$ & $-5.48 \%{ }^{*}$ & $48.99 \%{ }^{\star \star}$ & $-10.86 \%{ }^{\star \star}$ & $-25.55 \%{ }^{\star \star}$ & $-5.85 \%{ }^{*}$ \\
\hline & & $\begin{array}{l}\text { OPR1- } \\
\text { OE }\end{array}$ & $9.5163 \pm 1.048$ & $1.3951 \pm 0.438$ & 10.9114 & $20.5827 \pm 1.609$ & $32.2019 \pm 1.666$ & $19.79963 \pm 7.508$ & $18.3739 \pm 3.331$ \\
\hline & & $\begin{array}{l}\text { Increase } \\
\text { or } \\
\text { decrease }\end{array}$ & $21.21 \%$ ** & $-52.66 \%{ }^{* *}$ & $1.05 \%$ & $35.90 \%{ }^{* \star}$ & $14.17 \%{ }^{* *}$ & $3.58 \%{ }^{*}$ & $-7.78 \%{ }^{*}$ \\
\hline & \multirow[t]{4}{*}{ OPR2 } & OPR2i & $7.2108 \pm 0.384$ & $3.2877 \pm 0.183$ & 10.4985 & $16.8825 \pm 1.533$ & $26.7364 \pm 3.095$ & $17.4696 \pm 1.08$ & $19.9638 \pm 0.183$ \\
\hline & & $\begin{array}{l}\text { Increase } \\
\text { or } \\
\text { decrease }\end{array}$ & $-8.15 \%^{*}$ & $11.56 \%{ }^{* *}$ & $-2.77 \%^{*}$ & $11.47 \%^{* *}$ & $-5.20 \%^{*}$ & $-8.61 \%^{*}$ & $0.19 \%$ \\
\hline & & $\begin{array}{l}\text { OPR2- } \\
\text { OE }\end{array}$ & $9.1207 \pm 0.584$ & $1.1043 \pm 0.523$ & 10.225 & $21.4321 \pm 3.32$ & $31.029 \pm 1.838$ & $17.0149 \pm 1.747$ & $18.1661 \pm 2.313$ \\
\hline & & $\begin{array}{l}\text { Increase } \\
\text { or } \\
\text { decrease }\end{array}$ & $16.17 \%{ }^{* *}$ & $-62.53 \%{ }^{* \star}$ & $-5.31 \%{ }^{*}$ & $41.51 \%{ }^{* *}$ & $10.02 \%^{*}$ & $-10.99 \%{ }^{*}$ & $-8.83 \%^{*}$ \\
\hline & \multirow[t]{4}{*}{ OPR3 } & OPR3i & $7.3383 \pm 0.438$ & $2.8731 \pm 1.018$ & 10.2114 & $18.318 \pm 2.432$ & $27.7582 \pm 1.057$ & $17.5874 \pm 1.266$ & $19.3568 \pm 0.831$ \\
\hline & & $\begin{array}{l}\text { Increase } \\
\text { or } \\
\text { decrease }\end{array}$ & $-6.53 \%^{*}$ & $-2.51 \%$ & $-5.43 \%$ & $20.95 \%{ }^{* *}$ & $-1.58 \%$ & $-7.99 \%^{*}$ & $-2.85 \%$ \\
\hline & & $\begin{array}{l}\text { OPR3- } \\
\text { OE }\end{array}$ & $10.2309 \pm 1.924$ & $1.351 \pm 0.566$ & 11.5819 & $22.9638 \pm 1.382$ & $32.2931 \pm 3.819$ & $18.9167 \pm 2.314$ & $14.2964 \pm 1.938$ \\
\hline & & $\begin{array}{l}\text { Increase } \\
\text { or } \\
\text { decrease }\end{array}$ & $30.31 \%{ }^{* *}$ & $-54.16 \%{ }^{* \star}$ & $7.26 \%{ }^{*}$ & $51.63 \%{ }^{* *}$ & $14.50 \%{ }^{* *}$ & $-1.04 \%$ & $-28.25 \%{ }^{\star *}$ \\
\hline & \multirow[t]{4}{*}{ OPR4 } & OPR4i & $7.3477 \pm 0.29$ & $3.0894 \pm 0.253$ & 10.4371 & $19.9233 \pm 5.850$ & $26.4398 \pm 3.586$ & $16.0365 \pm 2.200$ & $18.3035 \pm 2.500$ \\
\hline & & $\begin{array}{l}\text { Increase } \\
\text { or } \\
\text { decrease }\end{array}$ & $-6.41 \%{ }^{*}$ & $4.83 \%^{*}$ & $-3.34 \%$ & $31.55 \%{ }^{* \star}$ & $-6.26 \%{ }^{*}$ & $-16.11 \%{ }^{\star \star}$ & $-8.14 \%^{*}$ \\
\hline & & $\begin{array}{l}\text { OPR4- } \\
\text { OE }\end{array}$ & $9.5807 \pm 0.799$ & $1.0081 \pm 0.340$ & 10.5888 & $20.9489 \pm 3.030$ & $31.4643 \pm 0.984$ & $19.8484 \pm 7.047$ & $15.3593 \pm 1.484$ \\
\hline & & $\begin{array}{l}\text { Increase } \\
\text { or } \\
\text { decrease }\end{array}$ & $22.03 \%{ }^{* \star}$ & $-65.79 \%{ }^{* \star}$ & $-1.94 \%$ & $38.32 \%{ }^{* \star}$ & $11.56 \%{ }^{* *}$ & $3.84 \%{ }^{*}$ & $-22.91 \%{ }^{* *}$ \\
\hline \multirow[t]{10}{*}{$\mathrm{T}_{2}$} & \multicolumn{2}{|c|}{ Contrast $T_{2}$} & $9.09 \pm 0.564$ & $3.48 \pm .0154$ & 12.57 & $11.742 \pm 2.154$ & $27.486 \pm 2.345$ & $20.848 \pm 1.253$ & $18.165 \pm 2.078$ \\
\hline & \multirow[t]{4}{*}{ OPR1 } & OPR1i & $8.463 \pm 0.246$ & $3.59 \pm 0.784$ & 12.053 & $9.23 \pm 1.546$ & $27.3638 \pm 1.648$ & $23.574 \pm 5.791$ & $18.205 \pm 0.634$ \\
\hline & & $\begin{array}{l}\text { Increase } \\
\text { or } \\
\text { decrease }\end{array}$ & $-6.90 \%{ }^{*}$ & $3.16 \%{ }^{*}$ & $-4.11 \%^{*}$ & $-21.39 \%^{* *}$ & $-0.44 \%$ & $13.08 \%{ }^{* *}$ & $0.22 \%$ \\
\hline & & $\begin{array}{l}\text { OPR1- } \\
\text { OE }\end{array}$ & $10.217 \pm 0.794$ & $4.558 \pm 0.254$ & 14.775 & $9.897 \pm 2.364$ & $30.153 \pm 0.994$ & $21.122 \pm 2.164$ & $17.349 \pm 1.424$ \\
\hline & & $\begin{array}{l}\text { Increase } \\
\text { or } \\
\text { decrease }\end{array}$ & $12.40 \%{ }^{*}$ & $30.98 \%{ }^{* *}$ & $17.54 \%{ }^{* *}$ & $-15.71 \%{ }^{* *}$ & $9.70 \%{ }^{*}$ & $1.31 \%$ & $-4.49 \%^{*}$ \\
\hline & \multirow[t]{4}{*}{ OPR2 } & OPR2i & $8.42 \pm 0.284$ & $4.048 \pm 0.645$ & 12.468 & $8.578 \pm 3.045$ & $27.71 \pm 1.564$ & $22.432 \pm 1.578$ & $17.839 \pm 0.978$ \\
\hline & & $\begin{array}{l}\text { Increase } \\
\text { or } \\
\text { decrease }\end{array}$ & $-7.37 \%{ }^{*}$ & $16.32 \%{ }^{* *}$ & $-0.81 \%$ & $-26.95 \%{ }^{* *}$ & $0.81 \%$ & $7.60 \%{ }^{*}$ & $-1.79 \%$ \\
\hline & & $\begin{array}{l}\text { OPR2- } \\
\text { OE }\end{array}$ & $10.039 \pm 0.451$ & $5.191 \pm 0.214$ & 15.23 & $9.44 \pm 1.231$ & $30.056 \pm 0.597$ & $21.467 \pm 0.146$ & $15.291 \pm 0.548$ \\
\hline & & $\begin{array}{l}\text { Increase } \\
\text { or } \\
\text { decrease }\end{array}$ & $10.44 \%^{*}$ & $49.17 \%^{* *}$ & $21.16 \%$ ** & $-19.60 \%{ }^{* *}$ & $9.35 \%{ }^{*}$ & $2.97 \%$ & $-15.82 \%{ }^{* \star}$ \\
\hline & OPR3 & OPR3i & $8.856 \pm 0.854$ & $3.413 \pm 0.847$ & 12.269 & $8.259 \pm 1.254$ & $27.173 \pm 0.914$ & $24.266 \pm 0.147$ & $17.029 \pm 0.934$ \\
\hline
\end{tabular}




\begin{tabular}{|c|c|c|c|c|c|c|c|c|}
\hline & $\begin{array}{l}\text { Increase } \\
\text { or } \\
\text { decrease }\end{array}$ & $-2.57 \%$ & $-1.93 \%$ & $-2.39 \%$ & $-29.66 \%{ }^{* *}$ & $-1.14 \%$ & $16.39 \%$ ** & $-6.25 \%{ }^{*}$ \\
\hline & $\begin{array}{l}\text { OPR3- } \\
\text { OE }\end{array}$ & $9.433 \pm 1.349$ & $3.884 \pm 0.915$ & $13.317 \pm 1.015$ & $10.063 \pm 0.187$ & $28.715 \pm 0.942$ & $20.721 \pm 0.975$ & $16.84 \pm 0.943$ \\
\hline & $\begin{array}{l}\text { Increase } \\
\text { or } \\
\text { decrease }\end{array}$ & $3.77 \%$ & $11.61 \%$ ** & $5.94 \%{ }^{*}$ & $-14.30 \%{ }^{* *}$ & $4.47 \%{ }^{*}$ & $-0.61 \%$ & $-7.29 \%{ }^{*}$ \\
\hline \multirow[t]{4}{*}{ OPR4 } & OPR4i & $9.133 \pm 0.643$ & $3.454 \pm 0.916$ & $12.587 \pm 0.241$ & $7.517 \pm 1.214$ & $27.208 \pm 0.914$ & $24.708 \pm 0.511$ & $17.791 \pm 0.261$ \\
\hline & $\begin{array}{l}\text { Increase } \\
\text { or } \\
\text { decrease }\end{array}$ & $0.47 \%$ & $-0.75 \%$ & $0.14 \%$ & $-35.98 \%{ }^{* *}$ & $-1.01 \%$ & $18.51 \%{ }^{* \star}$ & $-2.06 \%$ \\
\hline & $\begin{array}{l}\text { OPR4- } \\
\text { OE }\end{array}$ & $8.757 \pm 0.814$ & $3.733 \pm 0.646$ & 12.49 & $11.382 \pm 1.134$ & $28.921 \pm 0.615$ & $20.511 \pm 0.647$ & $16.674 \pm 1.057$ \\
\hline & $\begin{array}{l}\text { Increase } \\
\text { or } \\
\text { decrease }\end{array}$ & $-3.66 \%$ & $7.27 \%^{*}$ & $-0.64 \%$ & $-3.07 \%$ & $5.22 \%^{*}$ & $-1.62 \%$ & $-8.21 \%{ }^{*}$ \\
\hline
\end{tabular}

Note:*. $\mathrm{P}<0.05 ;{ }^{*} .0 .01<\mathrm{P}<0.05$. The same as Table 6.

Table 6. Analysis of variance for the same trend of 35 s and RNAiTable 


\begin{tabular}{|c|c|c|c|c|c|}
\hline \multicolumn{2}{|c|}{ Strain } & \multirow{2}{*}{$\begin{array}{l}\text { Oleic acid } \\
22.5651 \pm 2.401\end{array}$} & \multirow{2}{*}{$\begin{array}{l}\text { Linolenic acid } \\
\text { - }\end{array}$} & \multirow{2}{*}{$\begin{array}{l}\text { Arachidonic acid } \\
18.7597 \pm 1.975\end{array}$} & \multirow{2}{*}{$\begin{array}{l}\text { Erucic acid } \\
\text { - }\end{array}$} \\
\hline $\mathrm{T}_{1}$ & OPR1i & & & & \\
\hline & OPR1-OE & $20.5827 \pm 1.609$ & - & $18.3739 \pm 3.331$ & - \\
\hline & Mean square & 19.65 & - & 0.744 & - \\
\hline & Mean square within group & 4.177 & - & 7.496 & - \\
\hline & F value & $4.705^{\star}$ & - & 0.099 & - \\
\hline & OPR2i & $16.8825 \pm 1.533$ & $17.4696 \pm 1.08$ & - & - \\
\hline & OPR2-OE & $21.4321 \pm 3.32$ & $17.0149 \pm 1.747$ & - & - \\
\hline & Mean square & 103.494 & 1.034 & - & - \\
\hline & Mean square within group & 6.685 & 2.109 & - & - \\
\hline & F value & $15.481^{\star \star}$ & 0.49 & - & - \\
\hline & OPR3i & $18.318 \pm 2.432$ & $17.5874 \pm 1.266$ & $19.3568 \pm 0.831$ & - \\
\hline & OPR3-OE & $22.9638 \pm 1.382$ & $18.9167 \pm 2.314$ & $14.2964 \pm 1.938$ & - \\
\hline & Mean square & 5.259 & 8.835 & 128.038 & - \\
\hline & Mean square within group & 21.703 & 14.921 & 4.662 & - \\
\hline & F value & 0.242 & 0.592 & $27.466^{\star *}$ & - \\
\hline & OPR4i & $19.9233 \pm 5.580$ & - & $18.3035 \pm 2.500$ & - \\
\hline & OPR4-OE & $20.9489 \pm 3.030$ & - & $15.3593 \pm 1.484$ & - \\
\hline & Mean square & 107.917 & - & 43.342 & - \\
\hline & Mean square within group & 46.968 & - & 4.225 & - \\
\hline & F value & $2.298^{\star}$ & - & $10.257^{\star \star}$ & - \\
\hline \multirow[t]{20}{*}{$\mathrm{T}_{2}$} & OPR1i & $9.23 \pm 1.546$ & $23.574 \pm 5.791$ & - & - \\
\hline & OPR1-OE & $9.897 \pm 2.364$ & $21.122 \pm 2.164$ & - & - \\
\hline & Mean square & 1.439 & 4.824 & - & - \\
\hline & Mean square within group & 1.0266 & 1.993 & - & - \\
\hline & F value & 1.401 & $2.420^{\star}$ & - & - \\
\hline & OPR2i & $8.578 \pm 3.045$ & $22.432 \pm 1.578$ & $17.839 \pm$ & $2.264 \pm 4.165$ \\
\hline & OPR2-OE & $9.44 \pm 1.231$ & $21.467 \pm 0.146$ & $15.291 \pm$ & $1.91 \pm 0.841$ \\
\hline & Mean square & 0.00002 & 11.601 & 1.559 & 0.047 \\
\hline & Mean square within group & 1.186 & 1.099 & 2.78 & 0.044 \\
\hline & F value & 0.00002 & $10.560^{\star \star}$ & 0.561 & 1.048 \\
\hline & OPR3i & $8.259 \pm 1.254$ & - & $17.029 \pm 0.934$ & $2.244 \pm 0.771$ \\
\hline & OPR3-OE & $10.063 \pm 0.187$ & - & $16.84 \pm 0.943$ & $2.147 \pm 0.143$ \\
\hline & Mean square & 3.855 & - & 36.954 & 0.666 \\
\hline & Mean square within group & 1.931 & - & 2.328 & 0.035 \\
\hline & F value & 1.997 & - & $15.877^{\star \star}$ & $18.799^{\star \star}$ \\
\hline & OPR4i & $7.517 \pm 1.214$ & - & $17.791 \pm 0.261$ & - \\
\hline & OPR4-OE & $11.382 \pm 1.134$ & - & $16.674 \pm 1.057$ & - \\
\hline & Mean square & 3.968 & - & 1.769 & - \\
\hline & Mean square within group & 1.654 & - & 8.573 & - \\
\hline & F value & $2.399^{\star}$ & - & 0.206 & - \\
\hline
\end{tabular}

Table 7 Primers for OPR genes amplification

Page 16/22 


\begin{tabular}{llll}
\multicolumn{1}{l}{$\begin{array}{l}\text { Target ID } \\
\text { GSBRNA2T00012422001 }\end{array}$} & (OPR1) & Primer name & Primer sequence (5'-3') \\
\cline { 3 - 4 } & & OPR1 BamHI-F & TCTGATCAAGAGACAGGATCCATGGAAAATGCAGTAGCGAAAG \\
\hline GSBRNA2T00135385001 & (OPR2) & OPR2 BamHI-F & TCTGATCAAGAGACAGGATCCATGGAAAACGTAGTAACGAAAC \\
\cline { 3 - 4 } & & OPR2 Sall-R & CATCGGTGCACTAGTGTCGACTTAACTAGCTGTTGAATCAAG \\
\hline GSBRNA2T00082938001 & (OPR3) & OPR3 BamHI-F & TCTGATCAAGAGACAGGATCCATGGAAAATGCAGTAGCGAAAC \\
\cline { 3 - 4 } & & OPR3 Sall-R & CATCGGTGCACTAGTGTCGACTTAAGCTTTTGATTCAAGAAAAG \\
\hline GSBRNA2T00094910001 & (OPR4) & OPR4 BamHI-F & TCTGATCAAGAGACAGGATCCATGGAAAACGTAGTGACGAAAC \\
\cline { 3 - 4 } & & OPR4 Sall-R & CATCGGTGCACTAGTGTCGACTTAACTAGCTGTTGAATCAAG
\end{tabular}

Note: the underline indicates the restriction site. the same as Table 8.

Table 8 RNAi primers

\begin{tabular}{lll} 
Gene name & Primer name & Primer sequence(5'-3') \\
\hline OPR1 & OPR1 Ri-PBF & GAGTCTCTCTGCAGGGATCCATGGAAAATGCAGTAGCG \\
\cline { 2 - 3 } OPR2 & OPR2 Ri-SXR & TTTCCAGGTCGACTCTAGAACCTTTGGCATGAACAGC \\
\cline { 2 - 3 } & OPR2 Ri-SXR & TTTCCAGGTCGACTCTAGAGCCTTTTGCATGAACAGC \\
\hline OPR3 & OPR3 Ri-PBF & GAGTCTCTCTGCAGGGATCCATGGAAAATGCAGTAGCG \\
\cline { 2 - 3 } & OPR3 Ri-SXR & TTTCCAGGTCGACTCTAGAACCTTTGGCATGAACAGC \\
\hline OPR4 & OPR4 Ri-PBF & GAGTCTCTCTGCAGGGATCCATGGAAAACGTAGTGACG \\
\hline & & \\
\hline & OPR4 Ri-SXR & TTTCCAGGTCGACTCTAGAACCTTTGGCATGAACAGC \\
\hline
\end{tabular}

\section{Figures}



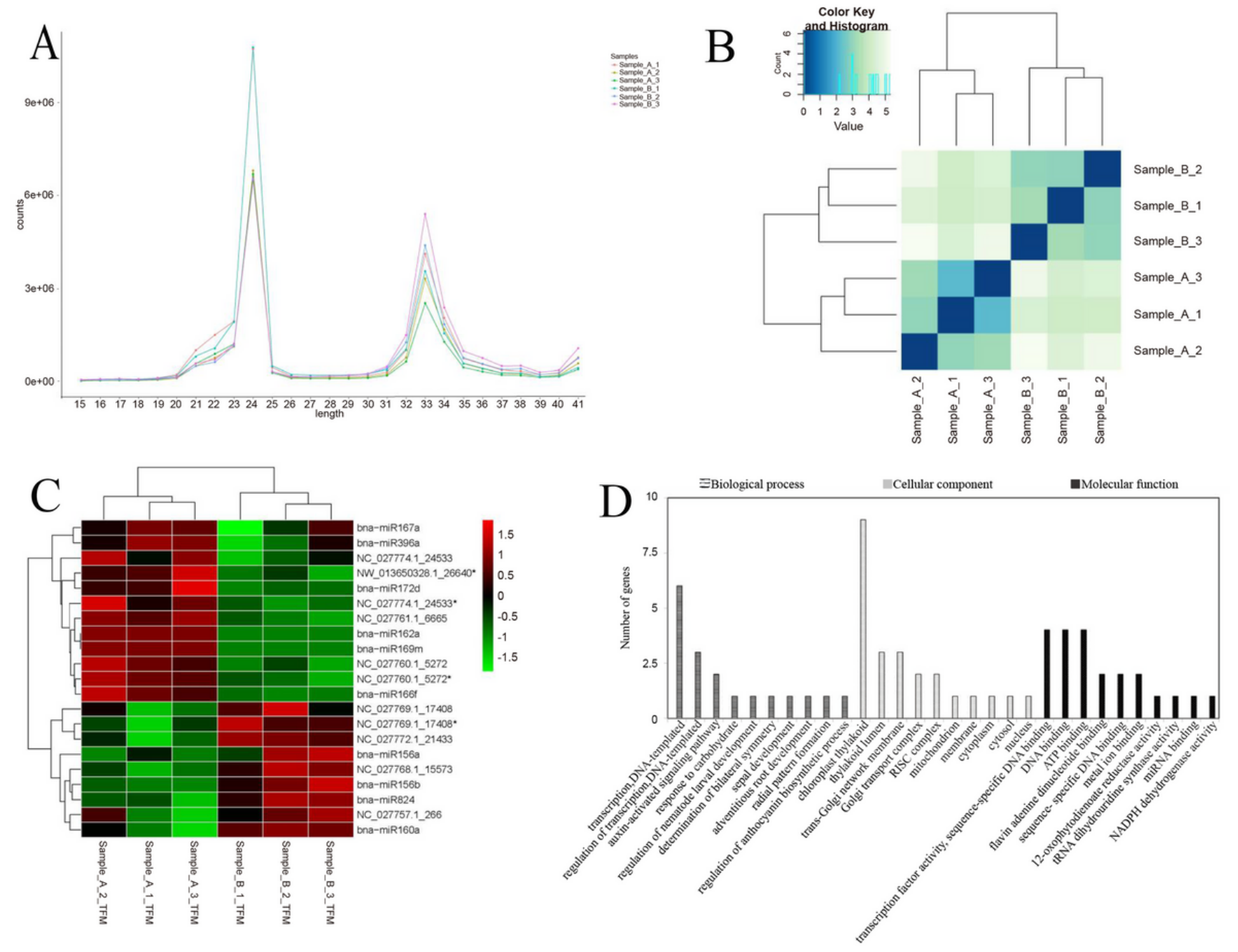

Figure 1

Sample size, sample-to-sample cluster and miRNAs cluster, GO enrichment analysis (A) Size distribution of the clean reads; (B) Results of sample-to-sample cluster analysis, Sample-A: Low oleic acid rapeseed materials; Sample-B: High oleic acid rapeseed materials; (C) Cluster distribution diagram of the different miRNAs; (D) GO enrichment analysis TOP10. 

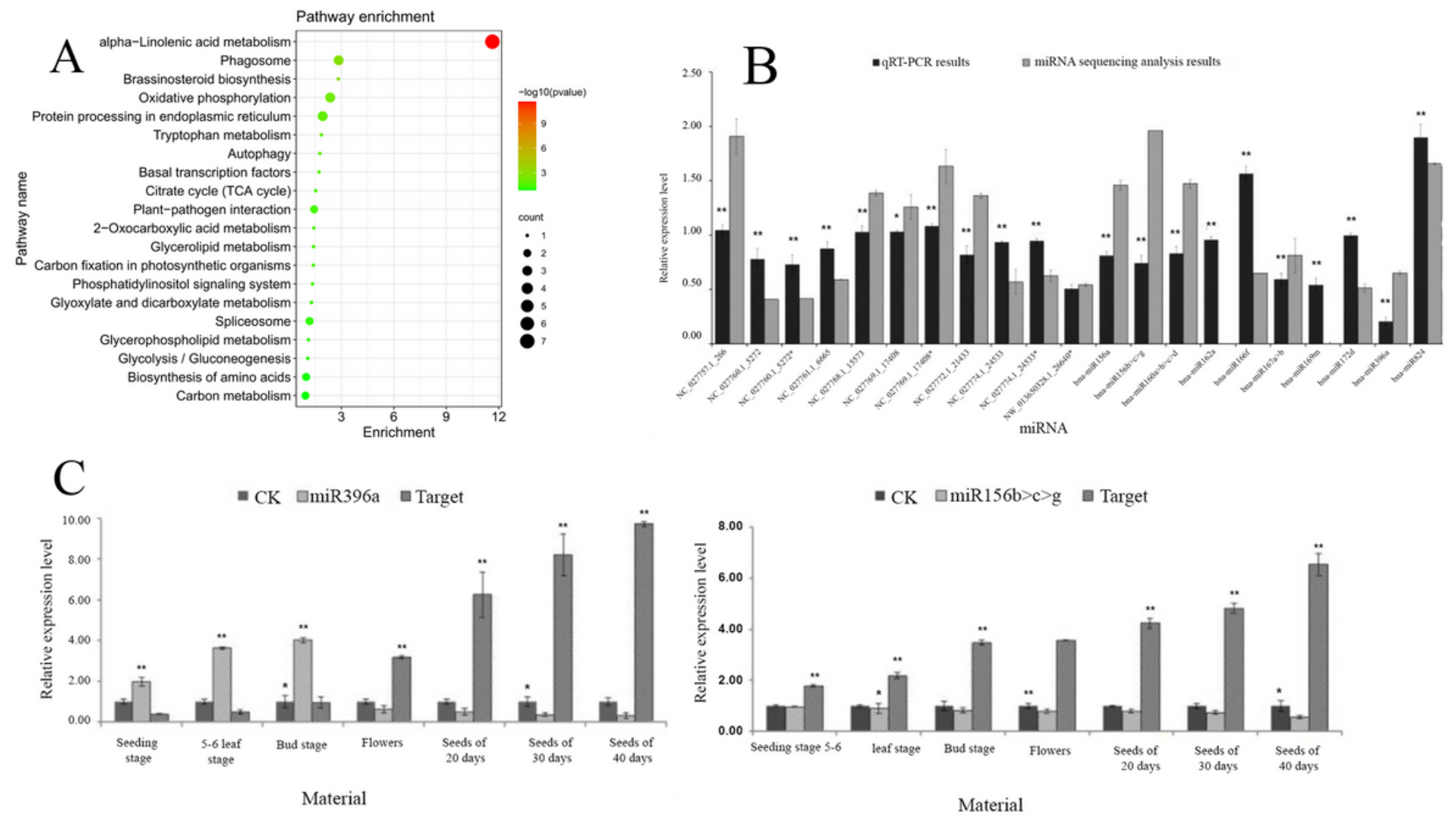

Figure 2

KEGG enrichments, RT-PCR results of miRNAs and the expressions of miRNAs and their target genes (A) Top 20 KEGG enrichments; (B) The RT-PCR results of 21 differential miRNAs. The results of low oleic acid rapeseed materials were used as control. (* and ** signify the difference level of $\mathrm{P}<0.05$ and $\mathrm{P}<0.01$, respectively); (C) The expressions of miRNAs (miR396a, miR1566b $>c>g$ ) and their target genes. The expression of miRNA and its target gene were used as controls. 

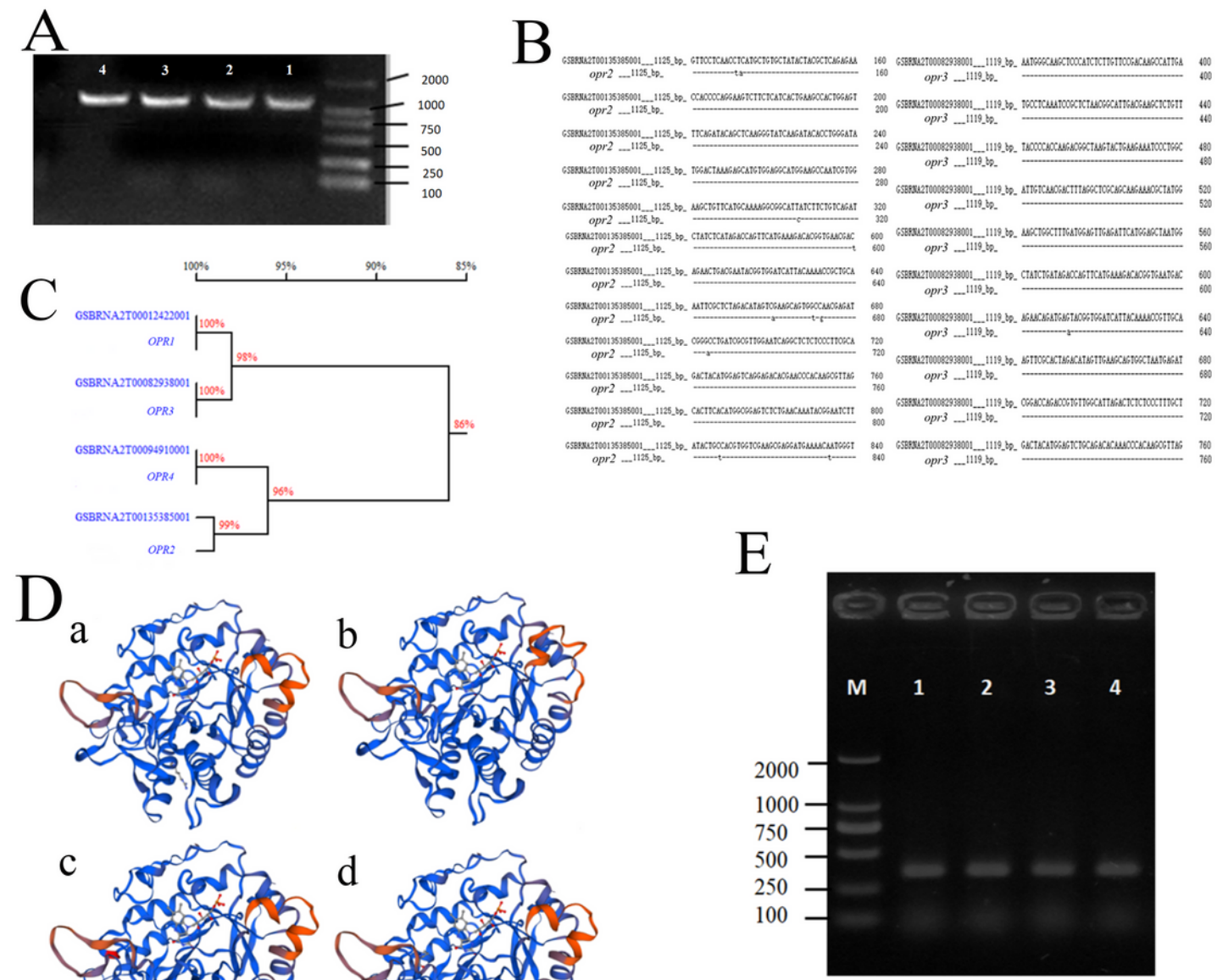

D
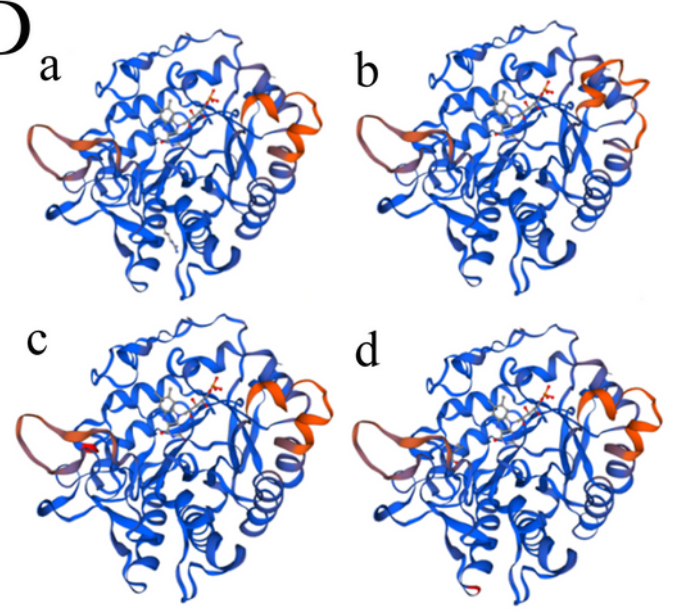

M: Trans $2000 ; 1$ : opr 1 ; 2 : opr2 ; 3: opr $3 ; 4:$ opr4

\section{Figure 3}

OPR genes PCR amplification, sequence and homology and the tertiary structure of protein analysis, RNAi fragment PCR amplification (A) Target gene PCR amplification (M: Trans 2000 bp; 1: OPR1; 2: OPR2; 3: OPR3 4: OPR4); (B) Sequence alignment with the sequence published in Brassica Database; (C) Sequence homology analysis with Brassica Database; (D) Tertiary structure of protein (A. OPR1; B. OPR2; C. OPR3; D. OPR4); (E) Objective Gene RNAi fragment PCR electrophoresis map. 


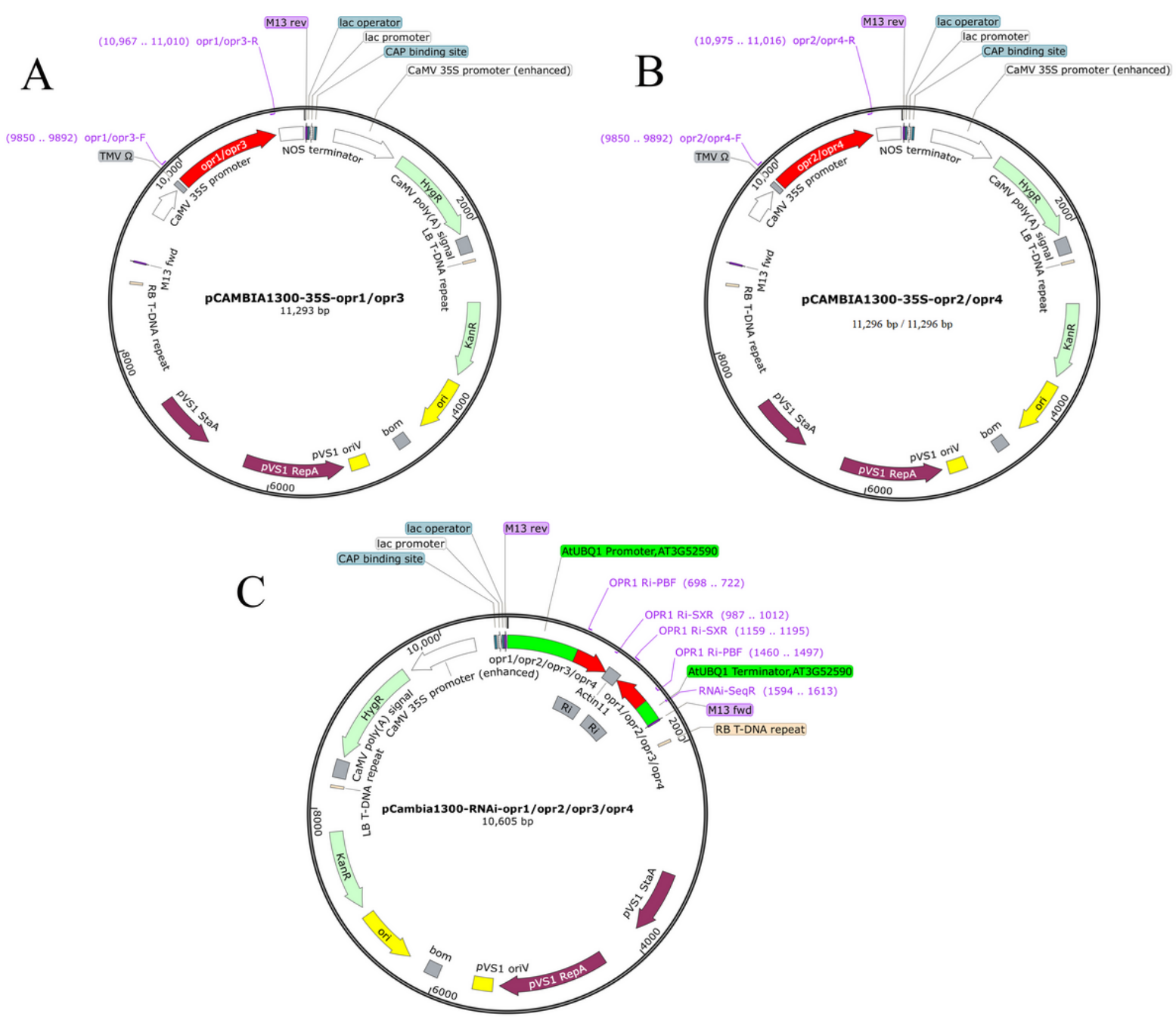

Figure 4

OPR genes 35s and RNAi recombinant vector map (A) and (B) pCAMBIA1300-35s-OPR1/OPR2/OPR3/OPR4 recombinant vector; (C) pCAMBIA1300-RNAiOPR1/OPR2/OPR3/OPR4 recombinant vector.
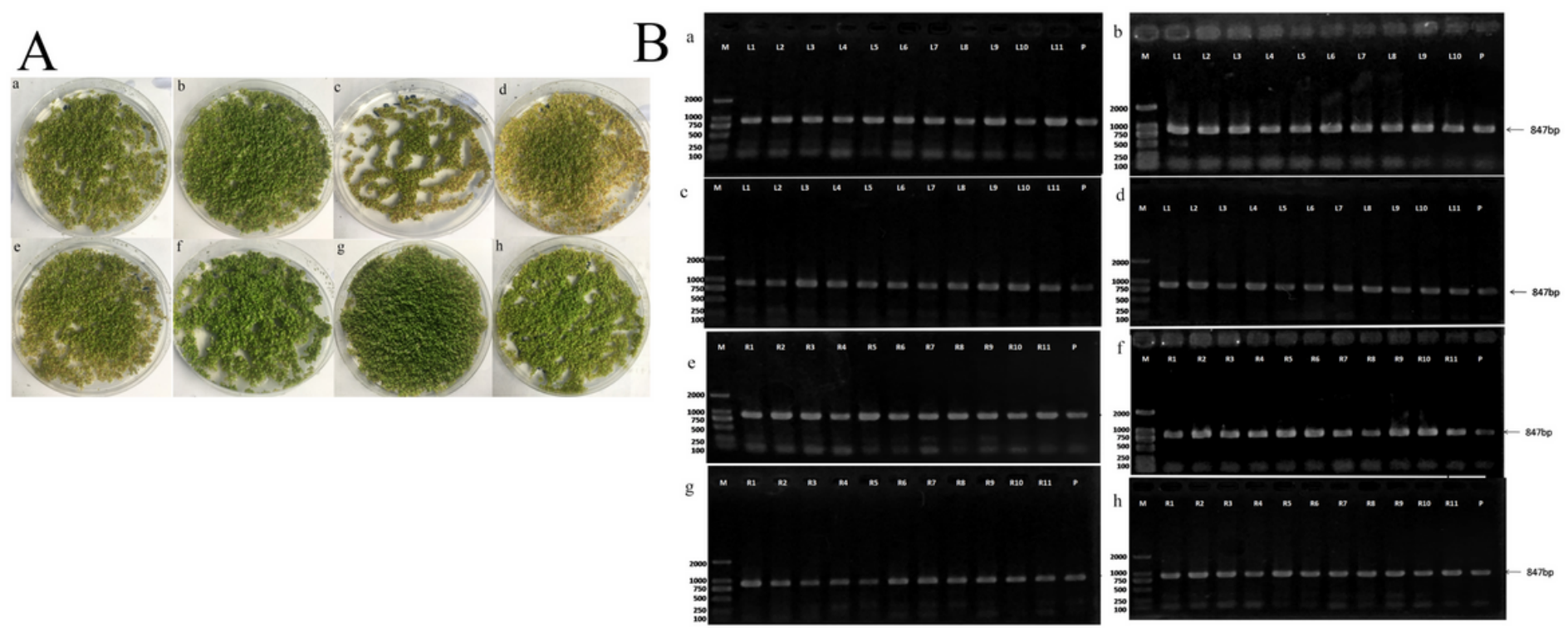

Figure 5 
Screening and identification of transgenic A. thaliana: (A) Hygromycin screening of transgenic $A$. thaliana. a/c/e/g: OPR1/2/3/4-OE; b/d/f/h: OPR1/2/3/4-OE; (B) Identification of hygromycin in transgenic A. thaliana (M: DL 2000 bp; P: pCAMBIA1300; a/c/e/g: pCAMBIA1300-35s-0PR1/2/3/4; b/d/f/h: pCAMBIA1300RNAi-OPR1/2/3/4).

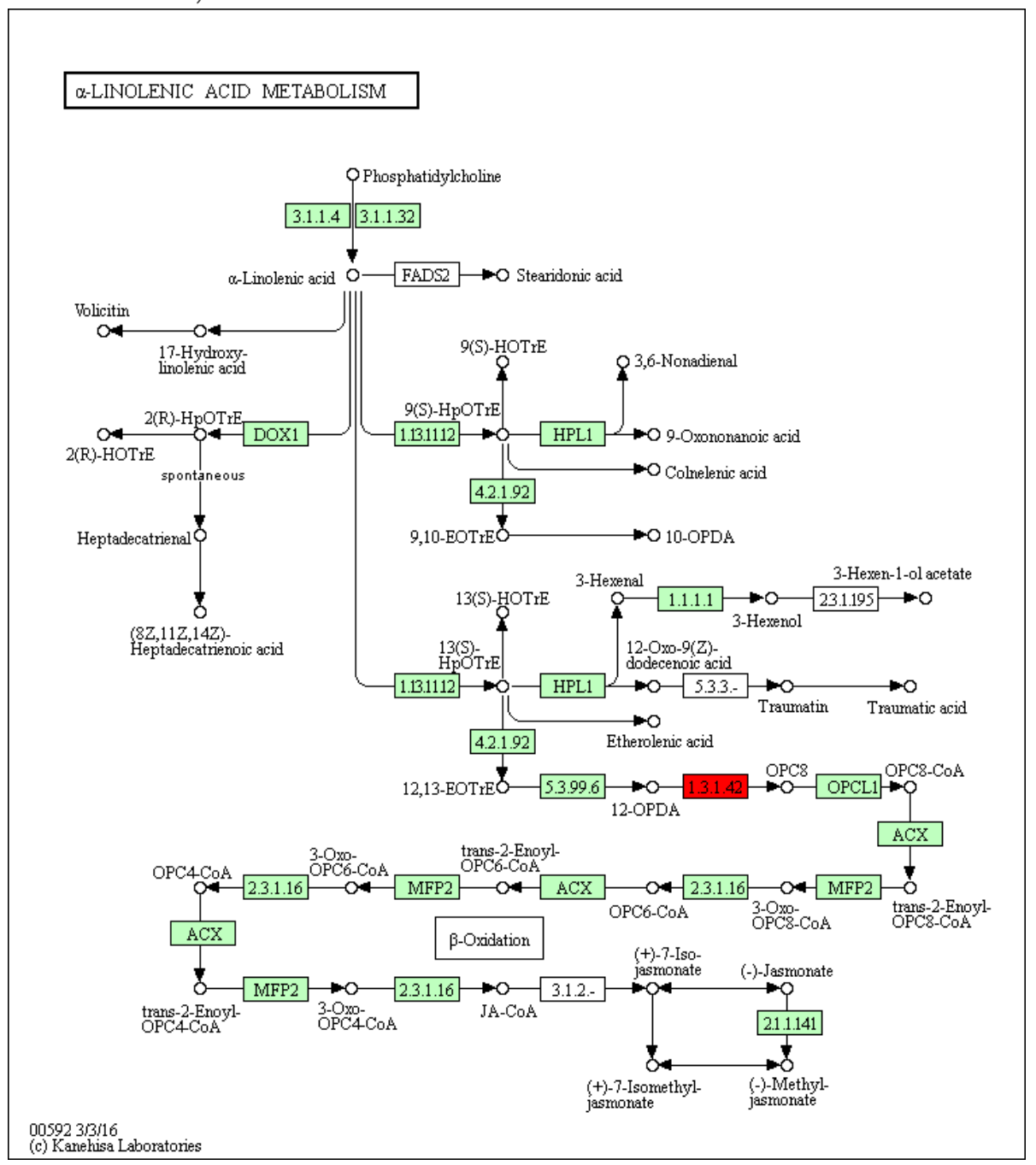

Figure 6

Bna00592 KEGG patway network.

\section{Supplementary Files}

This is a list of supplementary files associated with this preprint. Click to download.

- SupplementalTable2Thematuresequencesof....xlsx 